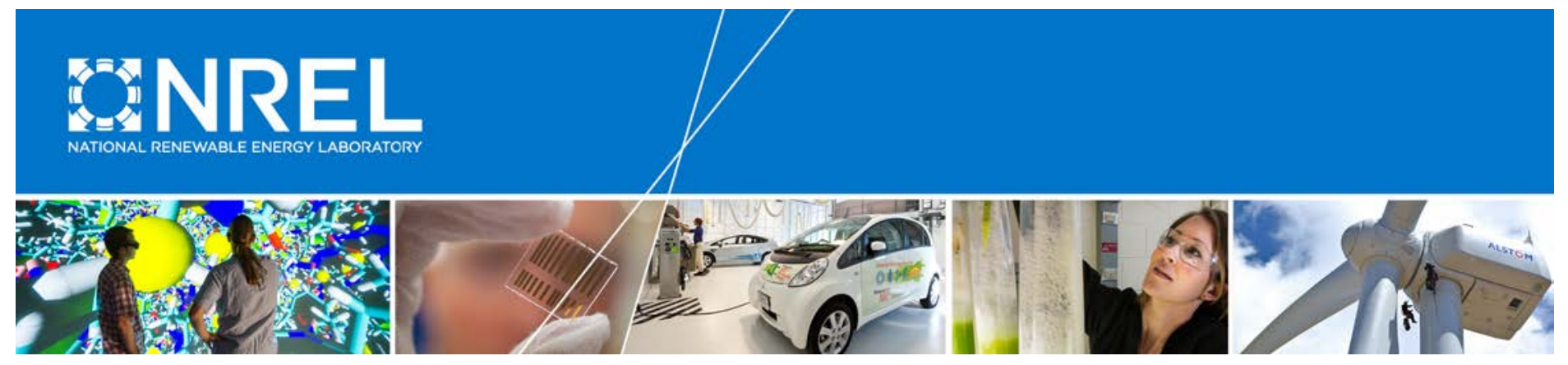

\title{
Electric Vehicles in Colorado: Anticipating Consumer Demand for Direct Current Fast Charging
}

Eric Wood and Clément Rames National Renewable Energy Laboratory (NREL)

Produced under direction of the Regional Air Quality Council (RAQC) and the Colorado Department of Transportation (CDOT) by the National Renewable Energy Laboratory (NREL)

NREL is a national laboratory of the U.S. Department of Energy Office of Energy Efficiency \& Renewable Energy Operated by the Alliance for Sustainable Energy, LLC

This report is available at no cost from the National Renewable Energy Laboratory (NREL) at www.nrel.gov/publications.

\section{Technical Report}

NREL/TP-5400-68447

July 2017 


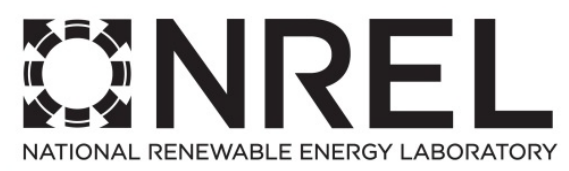

\section{Electric Vehicles in Colorado: Anticipating Consumer Demand for Direct Current Fast Charging}

Eric Wood and Clément Rames National Renewable Energy Laboratory (NREL)

Prepared under Technical Services Agreement No TSA-17900 and Task No. WTTN.1000

NREL is a national laboratory of the U.S. Department of Energy Office of Energy Efficiency \& Renewable Energy Operated by the Alliance for Sustainable Energy, LLC

This report is available at no cost from the National Renewable Energy Laboratory (NREL) at www.nrel.gov/publications.

National Renewable Energy Laboratory 15013 Denver West Parkway Golden, CO 80401

\section{Technical Report}

NREL/TP-5400-68447

July 2017

Contract No. DE-AC36-08G028308 


\section{NOTICE}

This report was prepared as an account of work sponsored by an agency of the United States government. Neither the United States government nor any agency thereof, nor any of their employees, makes any warranty, express or implied, or assumes any legal liability or responsibility for the accuracy, completeness, or usefulness of any information, apparatus, product, or process disclosed, or represents that its use would not infringe privately owned rights. Reference herein to any specific commercial product, process, or service by trade name, trademark, manufacturer, or otherwise does not necessarily constitute or imply its endorsement, recommendation, or favoring by the United States government or any agency thereof. The views and opinions of authors expressed herein do not necessarily state or reflect those of the United States government or any agency thereof.

This report is available at no cost from the National Renewable Energy Laboratory (NREL) at www.nrel.gov/publications.

Available electronically at SciTech Connect http:/www.osti.gov/scitech

Available for a processing fee to U.S. Department of Energy and its contractors, in paper, from:

U.S. Department of Energy

Office of Scientific and Technical Information

P.O. Box 62

Oak Ridge, TN 37831-0062

OSTI http://www.osti.gov

Phone: 865.576.8401

Fax: 865.576.5728

Email: reports@osti.gov

Available for sale to the public, in paper, from:

U.S. Department of Commerce

National Technical Information Service

5301 Shawnee Road

Alexandria, VA 22312

NTIS http://www.ntis.gov

Phone: 800.553 .6847 or 703.605 .6000

Fax: 703.605.6900

Email: orders@ntis.gov 


\section{Acknowledgments}

This study was supported by the Colorado Department of Transportation and the Regional Air Quality Council. The authors would specifically like to thank the following individuals for their guidance and support.

Tyler Svitak City and County of Denver

Christine Hoefler Colorado Department of Public Health and Environment

Paul Lee Colorado Department of Public Health and Environment

Phil von Hake. Colorado Department of Public Health and Environment

Michael King Colorado Department of Transportation

Peter Kozinski . Colorado Department of Transportation

Wes Maurer Colorado Department of Transportation

Maria Eisemann Colorado Energy Office

Zachary Owens Colorado Energy Office

Christian Williss Colorado Energy Office

Chris Worley Colorado Energy Office

Ken Lloyd Regional Air Quality Council

Steve McCannon Regional Air Quality Council

Matt Mines Regional Air Quality Council

Mike Salisbury Southwest Energy Efficiency Project

Will Toor. Southwest Energy Efficiency Project 


\section{List of Acronyms}

AADT
BEV
BEVxxx
BLAST-V
CDOT
DCFC
eVMT
FRTC
HPMS
IHS
L1
MUD
NREL
PEV
PHEVxx
SOC
SUD
VMT

annual average daily travel

battery electric vehicle

battery electric vehicle with a range of $\mathrm{xxx}$ miles

Battery Lifetime Analysis and Simulation Tool for

Vehicles

Colorado Department of Transportation

direct current fast charge

electric vehicle miles traveled

Front Range Travel Counts

Highway Performance Monitoring System

IHS Markit (formerly R.L. Polk)

Level 1 charging station

multiple-unit dwelling

National Renewable Energy Laboratory

plug-in electric vehicle (BEV or plug-in hybrid electric vehicle)

plug-in hybrid electric vehicle with a range of $\mathrm{xx}$ miles state of charge

single-unit dwelling

vehicle miles travelled 


\section{Table of Contents}

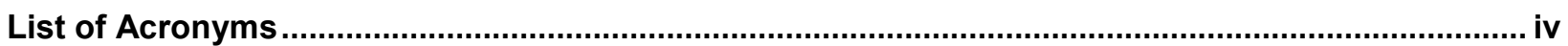

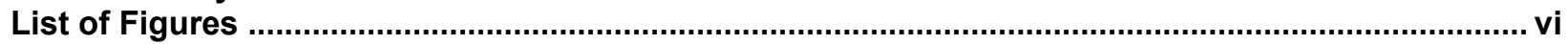

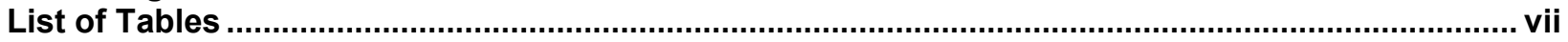

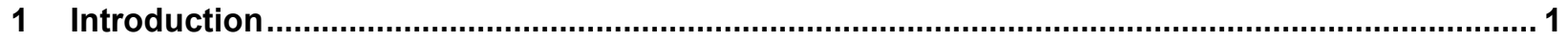

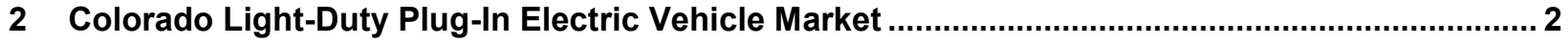

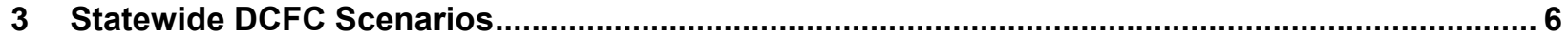

4 Front Range Travel Counts Household Survey....................................................................... 13

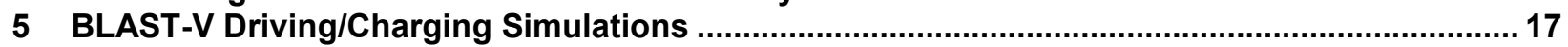

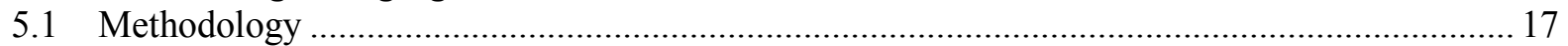

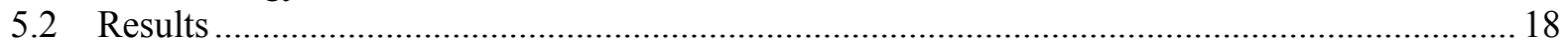

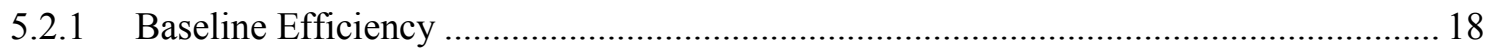

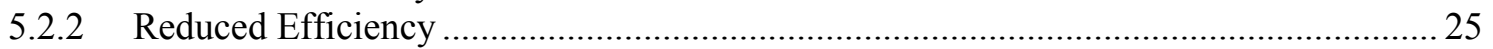

5.2.3 MUD Subset With No Home Charging .................................................................. 29

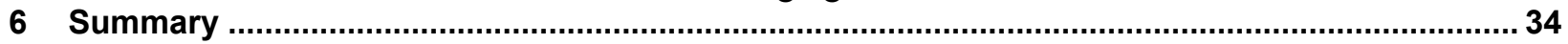

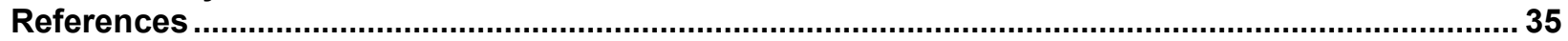




\section{List of Figures}

Figure 1. IHS PEV registrations by model across three regions (approximate totals through 2016) .......... 2

Figure 2. Colorado IHS PEV registrations by zip code (approximate totals through 2016)....................... 3

Figure 3. Denver metro IHS PEV registrations by zip code (approximate totals through 2016) ............... 4

Figure 4. AADT volumes from Federal Highway Administration HPMS (line thickness proportional to traffic volume).

Figure 5. Denver metropolitan area with roads sized by AADT. Magenta markers represent existing DCFC stations, and green markers show locations of hypothetical stations sited using an NREL algorithm to maximize traffic exposure (numeric values denote sequencing order

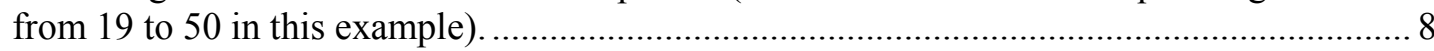

Figure 6. Existing scenario: Colorado's existing 18 DCFC stations...................................................... 10

Figure 7. Scenario 1: Colorado's existing 18 DCFC stations plus 50 stations sited by NREL algorithm (68

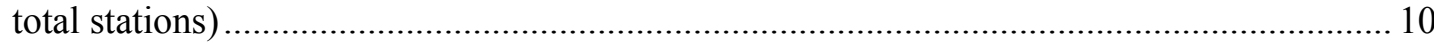

Figure 8. Scenario 2: Colorado's existing 18 DCFC stations plus 31 Interstate stations (49 total stations) 11

Figure 9. Scenario 3: Colorado's existing 18 DCFC stations plus 31 Interstate stations plus 50 stations

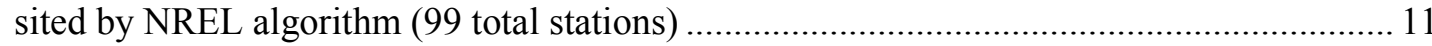

Figure 10. Scenario 4: Colorado's existing 18 DCFC stations plus 31 Interstate stations plus 47 highway stations (96 total stations)

Figure 11. Scenario 5: Colorado's existing 18 DCFC stations plus 31 Interstate stations plus 47 highway stations plus 50 stations sited by NREL algorithm (146 total stations) .................................. 12

Figure 12. FRTC survey trip destinations (personal car only) ............................................................. 13

Figure 13. Hypothetical origin-destination pair with three route alternatives (overlaid with existing DCFC

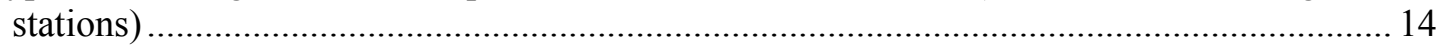

Figure 14. Heat map of FRTC estimated driving routes used in BLAST-V simulations ......................... 15

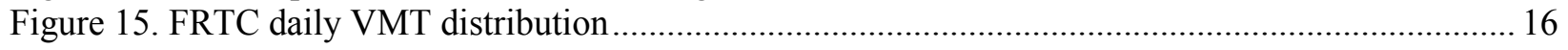

Figure 16. Simulated fleet percent eVMT by BEV type and DCFC network …..................................... 18

Figure 17. Simulated DCFC station utilization by BEV type and DCFC network.................................. 19

Figure 18. Simulated DCFC station utilization, marker size proportional to station charge events (BEV100, existing stations, and baseline efficiency) ........................................................ 20

Figure 19. Simulated DCFC station utilization, marker size proportional to station charge events (BEV100, DCFC Scenario 1, and baseline efficiency) ........................................................ 21

Figure 20. Simulated DCFC station utilization, marker size proportional to station charge events (BEV100, DCFC Scenario 2, and baseline efficiency) ......................................................... 21

Figure 21. Simulated DCFC station utilization, marker size proportional to station charge events

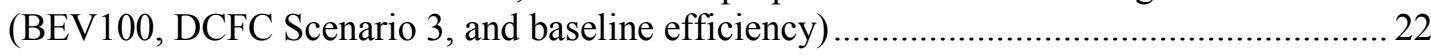

Figure 22. Simulated DCFC station utilization, marker size proportional to station charge events (BEV100, DCFC Scenario 4, and baseline efficiency) ........................................................ 22

Figure 23. Simulated DCFC station utilization, marker size proportional to station charge events

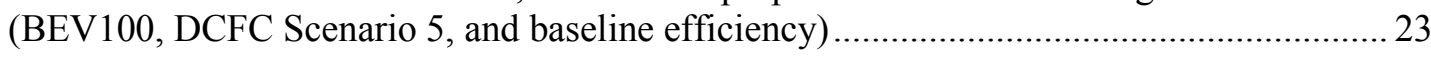

Figure 24. Simulated DCFC station utilization, marker size proportional to station charge events (BEV200, DCFC Scenario 5, and baseline efficiency) ...................................................... 24

Figure 25. Simulated DCFC station utilization, marker size proportional to station charge events (BEV300, DCFC Scenario 5, and baseline efficiency) ..................................................... 24

Figure 26. Simulated charging load profile by charger type (BEV100, DCFC Scenario 5, and baseline

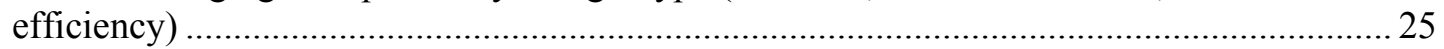

Figure 27. Simulated fleet percent eVMT by BEV type and DCFC network (reduced efficiency scenario)26

Figure 28. Simulated DCFC station utilization by BEV type and DCFC network (reduced efficiency scenario)

Figure 29. Simulated DCFC station utilization, marker size proportional to station charge events (BEV100, DCFC Scenario 5, and reduced efficiency) 
Figure 30. Simulated DCFC station utilization, marker size proportional to station charge events (BEV200, DCFC Scenario 5, and reduced efficiency).

Figure 31. Simulated DCFC station utilization, marker size proportional to station charge events (BEV300, DCFC Scenario 5, and reduced efficiency)

Figure 32. Simulated fleet percent eVMT by BEV type and DCFC network (MUDs only with no home charging)

Figure 33. Simulated DCFC station utilization by BEV type and DCFC network (MUDs only with no home charging)

Figure 34. Simulated DCFC station utilization, marker size proportional to number of station charge events (BEV100, DCFC Scenario 1, and MUDs only with no home charging)....

Figure 35. Simulated DCFC station utilization, marker size proportional to number of station charge events (BEV200, DCFC Scenario 1, and MUDs only with no home charging).................... 32

Figure 36. Simulated DCFC station utilization, marker size proportional to number of station charge events (BEV300, DCFC Scenario 1, and MUDs only with no home charging)..................... 33

\section{List of Tables}

Table 1. IHS PEV Registrations by County (Top Ten Colorado Counties) 3

Table 2. Hypothetical DCFC Networks Developed for BLAST-V Simulation-Based Evaluations.....

Table 3. Vehicle Counts by Metropolitan Planning Organization from the Front Range Travel Counts Survey 


\section{Introduction}

The State of Colorado supports consumer adoption of electric vehicles to improve statewide air quality, reduce petroleum consumption from motor vehicles, and lower consumer transportation costs. This support is evident in the Alternative Fuel Motor Vehicle Income Tax Credits (made available via Colorado HB 16-1332), which provide Colorado motorists with tax credits up to $\$ 5,000$ towards the purchase of a light-duty electric vehicle (larger credits are available for commercial vehicles; eligible 2017-2022).

In addition to purchase incentives, consumer access to a robust network of publically accessible direct current fast charge (DCFC) stations helps enable increased consumer adoption of battery electric vehicles (BEVs). As the State of Colorado considers the opportunity for public and private investments in charging station infrastructure to support BEVs (such as Volkswagen's plan to invest \$2 billion in U.S. zero emission vehicle infrastructure between 2017 and 2026 including $\$ 68.5$ million anticipated for investment in Colorado [Volkswagen Group of America 2017]), reliable estimates of consumer demand for and utilization of DCFC infrastructure are needed.

To support the State of Colorado in planning for DCFC infrastructure growth, the National Renewable Energy Laboratory (NREL) has partnered with the Regional Air Quality Council and the Colorado Department of Transportation (CDOT) to analyze a number of DCFC investment scenarios. NREL's analysis consisted of coupling detailed weekday travel data from the Front Range Travel Counts (FRTC) survey to its Battery Lifetime Analysis and Simulation Tool for Vehicles (BLAST-V), which was developed under funding from the U.S. Department of Energy's Vehicle Technologies Office, to estimate the potential impacts of various DCFC scenarios in Colorado. NREL's analysis complements ongoing DCFC studies by various state and local entities, including the Colorado Energy Office, the Colorado Department of Public Health and Environment, and the City and County of Denver [Denver's Opportunity for Vehicle Electrification: Overcoming Charging Challenges to Maximize Air Quality Benefits (Department Environmental Health, City and County of Denver, forthcoming)].

NREL analyzed existing electric vehicle registration data from IHS Markit (IHS) to highlight early trends in the BEV market, which were compared with sales forecasts predicting large growth in the Colorado electric vehicle market. Electric vehicle forecasts were then used to develop future DCFC scenarios to be evaluated in BLAST-V simulations. One of the primary inputs for the BLAST-V model is real-world travel profiles from individual consumers, which were sourced from the FRTC survey. BLAST-V was then used to estimate consumer benefits of the hypothetical DCFC networks in terms of increased driving range and electric vehicle miles traveled (eVMT). Simulated utilization of the hypothetical DCFC networks was analyzed for geographic trends, particularly for correlations with vehicle electric range. Finally, a subset of simulations is presented for consumers with potentially inconsistent access to charging at their home location and presumably greater reliance on public DCFC infrastructure. 


\section{Colorado Light-Duty Plug-In Electric Vehicle Market}

IHS vehicle registration data are used as a source for the existing light-duty vehicle fleet in Colorado as of the end of 2016. Approximately 8,600 plug-in electric vehicles (PEVs) were registered in Colorado as of the end of 2016. Compared to a total of approximately 5 million light-duty vehicles PEVs represented $0.17 \%$ of the light-duty fleet (PEVs represented $0.82 \%$ of the fleet when isolating to model year 2016 registrations).

Figure 1 illustrates PEV stock for the ten top-selling PEV models in the United States (Chevrolet Volt, Nissan Leaf, Tesla Model S, Toyota Plug-In Prius, Ford Fusion Energi, Ford C-Max Energi, Fiat 500e, BMW i3 REx, Tesla Model X, and Volkswagen e-Golf) across three geographic regions (California, United States less California, and Colorado). Given the large share of PEV sales in California, the United States is divided into a California group (238,000 PEVs) and a United States less California group (262,400 PEVs) (both totals approximate).

PEV Shares, 2016 Polk Registrations

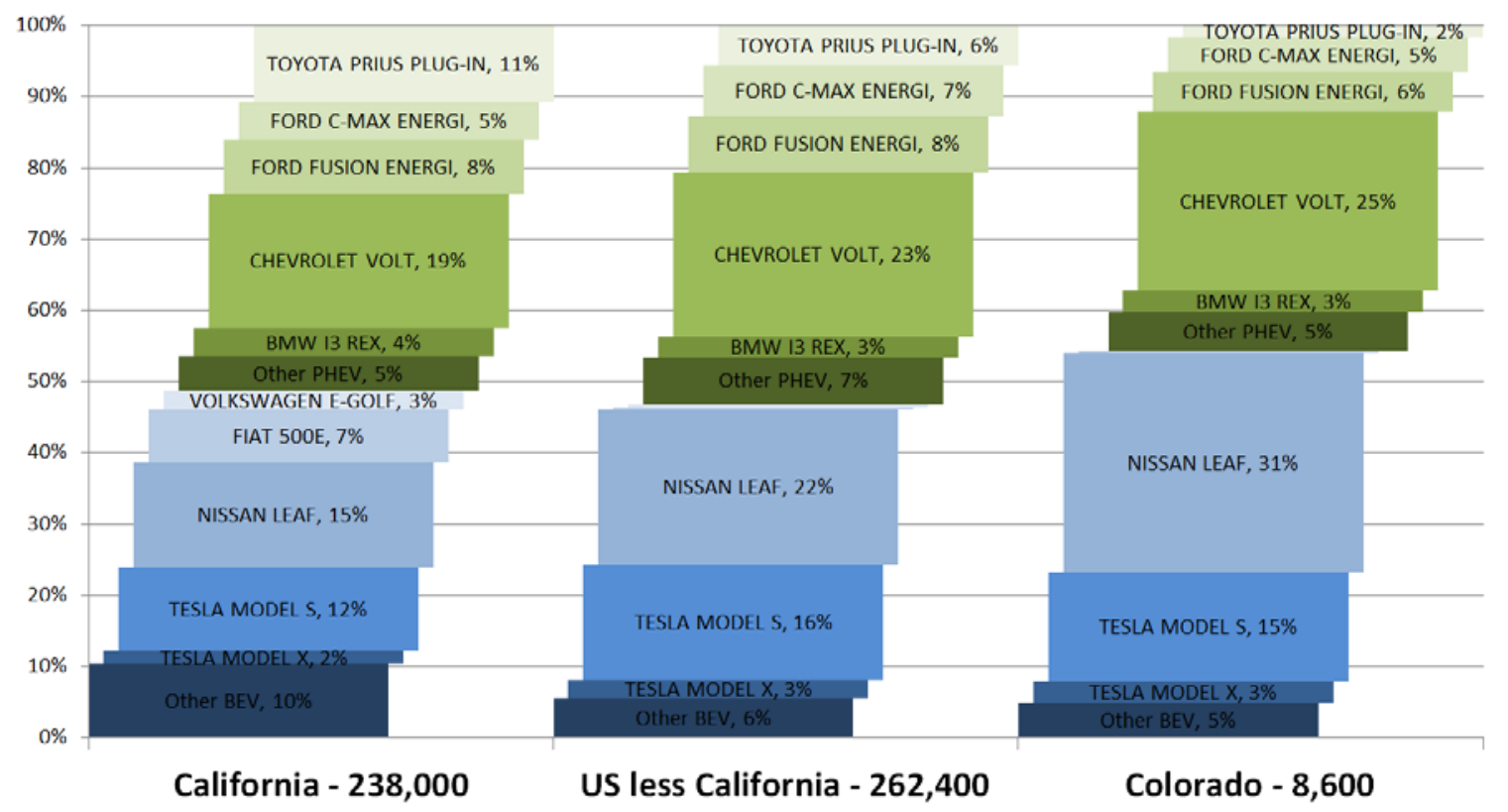

Figure 1. IHS PEV registrations by model across three regions (approximate totals through 2016)

The data reveal some interesting trends for PEV adoption. California's influence on the overall U.S. PEV stock is most evident in the $10 \%$ share of BEVs falling outside the top ten PEV models. This share drops to $6 \%$ when California is excluded, possibly reflecting the presence of BEV models that are exclusively available in California (such as the Fiat 500e and Volkswagen e-Golf). Overall, the relatively successful PEV market in California is more heterogeneous than the Colorado market. The top three models in California (Chevrolet Volt, Nissan Leaf, and Tesla Model S) constitute $45 \%$ of the PEV stock in that state, whereas the same three models make up $71 \%$ of the PEV stock in Colorado.

Colorado's PEV stock contains a higher percentage of BEVs than the United States as a whole. Approximately 54\% of Colorado PEVs are BEVs (compared to 48\% nationally). Looking 
specifically at model year 2016 PEVs in Colorado the BEV share increases to 69\%, potentially denoting an increasing BEV preference and/or availability for purchase.

Colorado PEVs are currently concentrated along the I-25 corridor with over $90 \%$ of PEVs registered in ten Front Range counties as shown in Table 1. Maps of PEV registrations by zip code are shown in Figures 2 and 3 (Colorado and Front Range respectively).

Table 1. IHS PEV Registrations by County (Top Ten Colorado Counties)

\begin{tabular}{lc}
\hline County Name & PEV Registrations \\
\hline BOULDER & 1,600 \\
DENVER & 1,100 \\
JEFFERSON & 1,100 \\
ARAPAHOE & 1,000 \\
DOUGLAS & 800 \\
LARIMER & 700 \\
EL PASO & 700 \\
ADAMS & 500 \\
WELD & 300 \\
BROOMFIELD & 200 \\
\hline
\end{tabular}

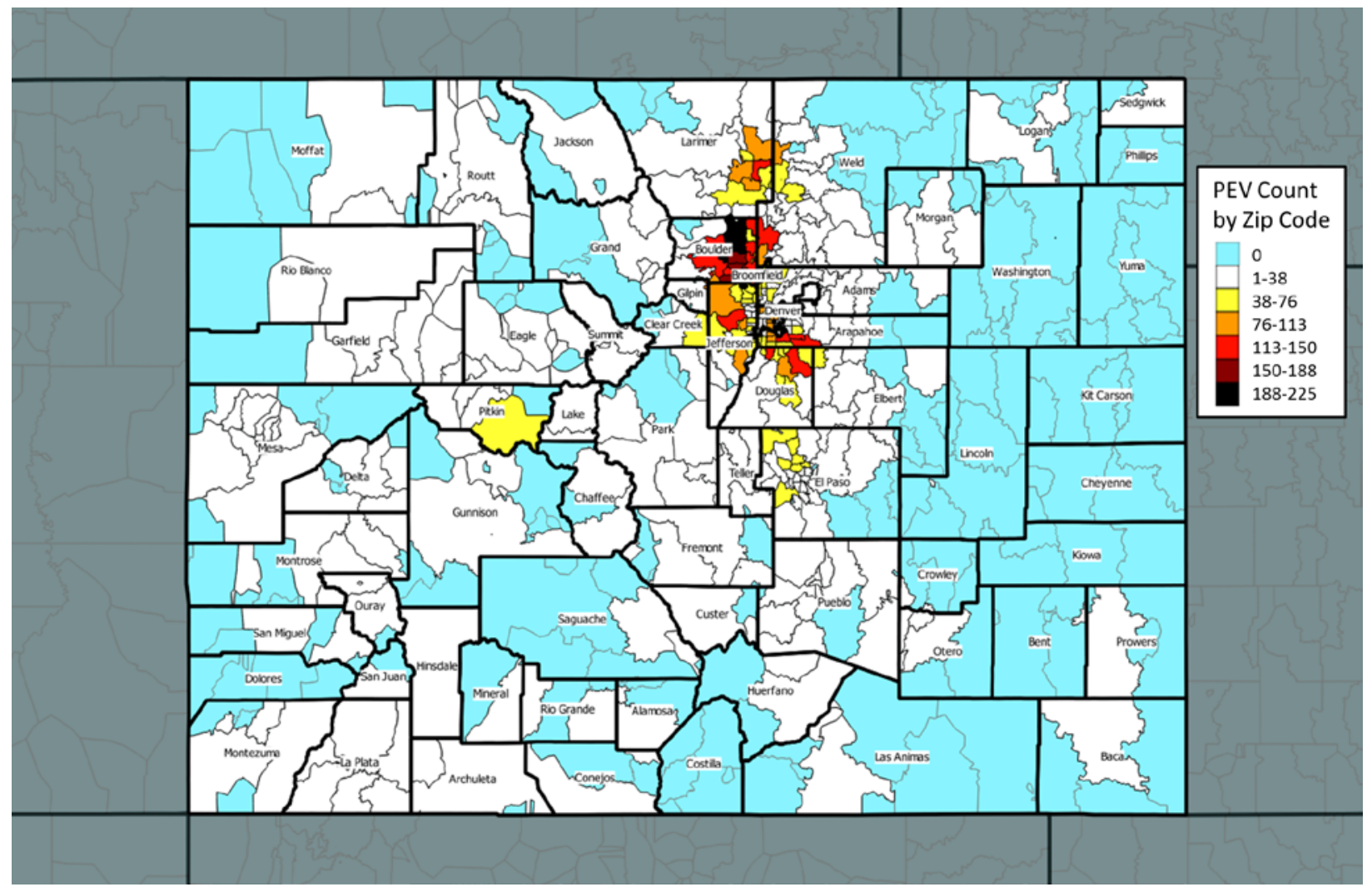

Figure 2. Colorado IHS PEV registrations by zip code (approximate totals through 2016) 


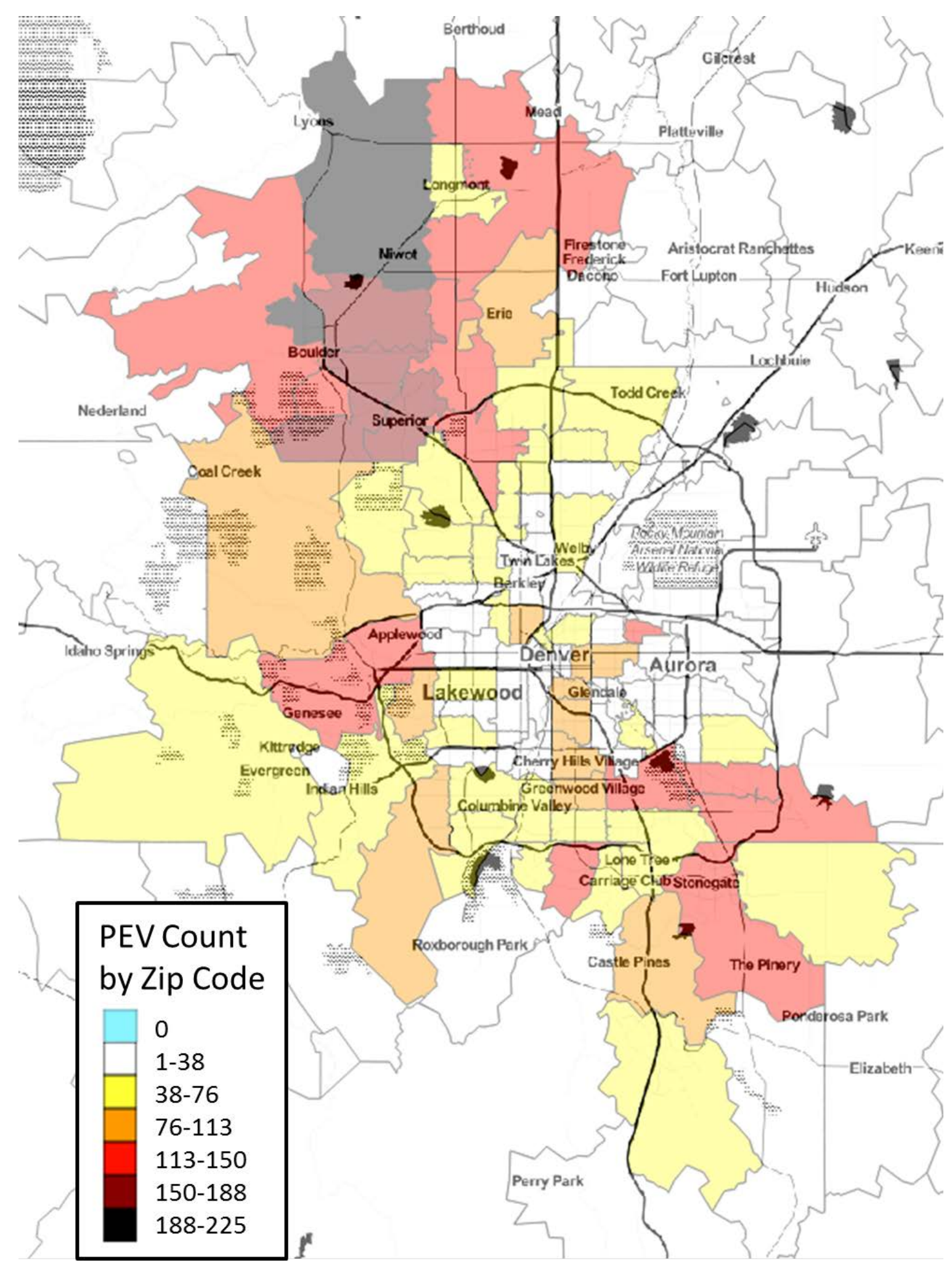

Figure 3. Denver metro IHS PEV registrations by zip code (approximate totals through 2016) 
While early PEV market data provide a glimpse into early adopter preferences, it is important to remember that these markets are still in their infancy. Bloomberg New Energy Finance estimates that by 2020 over 120 electric vehicle models will be available to consumers, including vehicles such as the Chevrolet Bolt, Tesla Model 3, and $2^{\text {nd }}$ generation Nissan Leaf [Bloomberg New Energy Finance]. A 2015 report by the Colorado Energy Office developed three PEV growth scenarios with sales and stock projections from 2014 to 2030 (Colorado Energy Office 2015). Growth scenarios in this report are categorized as Low, Medium, and High with the total number of PEVs on the road in 2030 as 38,056 (low), 302,429 (medium), and 937,216 (high). These scenarios represent PEVs accounting for $0.63 \%$ (low), $5.0 \%$ (medium), and $15.5 \%$ (high) of all light-duty vehicles on Colorado roads in 2030. 


\section{Statewide DCFC Scenarios}

Using the Colorado Energy Office medium-growth scenario for 302,429 PEVs on Colorado roads in 2030, a number of hypothetical DCFC networks were developed. An estimate of the total number of DCFC stations was generated to place an upper bound on the network design problem.

A number of previous studies have quantified DCFC requirements as ratios of DCFC plugs necessary to support 1,000 BEVs. NREL's report California Statewide Plug-In Electric Vehicle Infrastructure Assessment for the California Energy Commission derived a requirement of 1.9 to 5.2 DCFC plugs per 1,000 BEVs [Melaina and Helwig 2014]. A 2014 report by the Electric Power Research Institute estimated that approximately five DCFC plugs were required to support 1,000 BEVs [Davis and Alexander 2014]. More recently, a 2017 NREL case study of Massachusetts estimated two to nine DCFC plugs per 1,000 BEVs [Wood et al. 2017]. Each of these studies arrives at a relatively low number of DCFC plugs per BEV ratio due to an underlying assumption regarding the availability of home charging for the majority of $\mathrm{BEV}$ owners.

Assuming 302,429 PEVs (per the Colorado Energy Office's medium-growth scenario) and a $54 \%$ market share for BEVs (per IHS data), a total of 163,312 BEVs could be on Colorado roads in 2030. Using a nominal value of five DCFC plugs per 1,000 BEVs (per studies cited above), a total of 817 DCFC plugs would be necessary to support consumers. Information from the U.S. Department of Energy's Alternative Fuels Data Center website shows that existing DCFC stations currently provide an average of 2.5 plugs per station. As PEV technology continues to mature, it is likely that more plugs will be required per station to minimize consumer queuing during peak hours. Assuming future stations are constructed with four DCFC plugs per station, a total of 204 DCFC stations would be necessary to meet consumer demand in 2030. Applying the same logic to the Colorado Energy Office medium-growth scenario estimate of 80,000 PEVs in 2020 would result in a total of 54 DCFC stations.

While bulk estimates of DCFC station and plug counts are helpful for PEV infrastructure planning, they do little to address issues related to geographic distribution of stations in urban areas and along highway corridors. A series of hypothetical DCFC networks in Colorado have been developed as inputs for simulation-based evaluations.

Broadly speaking, these networks attempt to satisfy two objectives: 1) place stations along highly travelled routes with high visibility (and potentially high utilization), and 2) place stations along major highway routes enabling long distance travel between cities and to popular Colorado destinations. Towards the first objective, traffic volumes are quantified using Colorado data from the Federal Highway Administration's Highway Performance Monitoring System (HPMS) (U.S. Department of Transportation). HPMS provides estimates of annual average daily travel (AADT) at the link level for all major highways and arterial streets (visualized at the state level in Figure 4). 


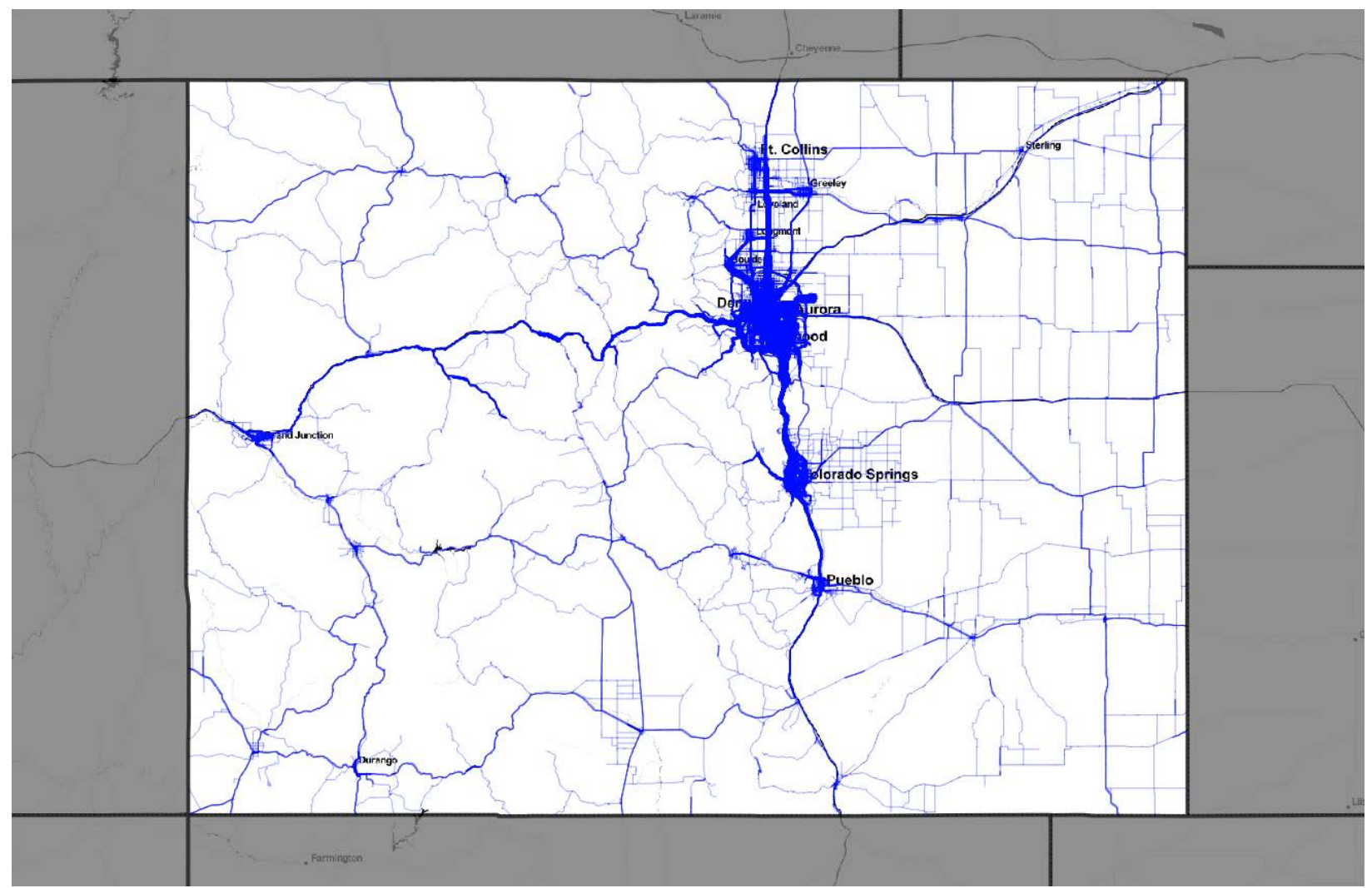

Figure 4. AADT volumes from Federal Highway Administration HPMS (line thickness proportional to traffic volume)

HPMS AADT data are used to programmatically backfill stations based on gaps in any arbitrary DCFC network using an NREL algorithm to locate hypothetical "traffic-based stations." For example, Figure 5 shows the Denver metropolitan area with road thickness sized by AADT values and existing DCFC station locations (overlaid using magenta markers). Green markers show locations of hypothetical "traffic-based stations" (located by the NREL algorithm) in which high AADT locations not covered by an existing DCFC station are identified as a hypothetical location for a new station. This approach is iterative and allows for any arbitrary DCFC network to be built with the objective of maximizing traffic exposure. 


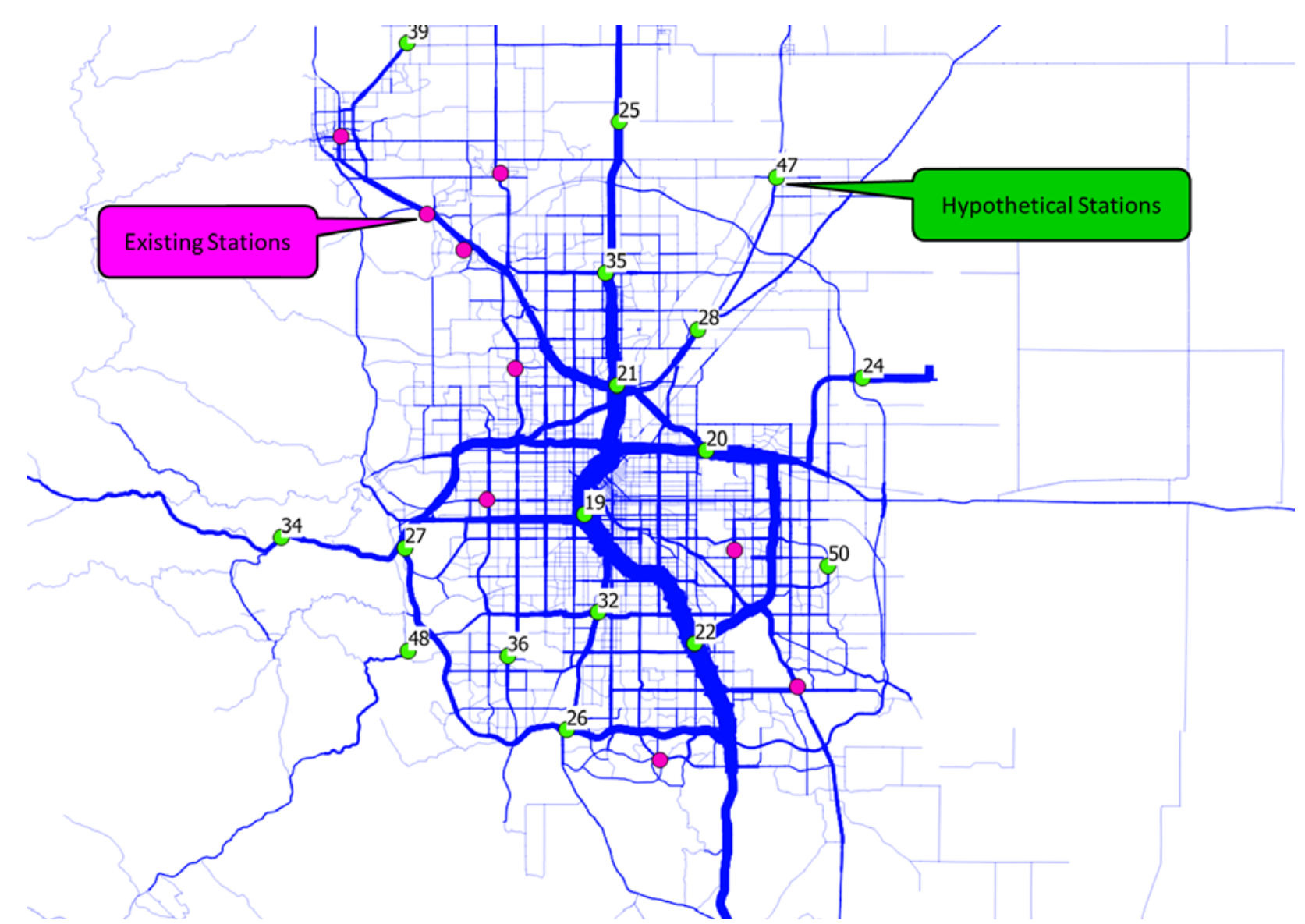

Figure 5. Denver metropolitan area with roads sized by AADT. Magenta markers represent existing DCFC stations, and green markers show locations of hypothetical stations sited using an NREL algorithm to maximize traffic exposure (numeric values denote sequencing order from 19 to 50 in this example).

Seven DCFC networks are constructed for simulation-based evaluation (shown in Table 1). The first network is referred to as the Baseline network and contains no DCFC stations, which allows for isolation of DCFC benefits relative to the other networks.

The second network represents the existing Colorado network of DCFC stations (per U.S. Department of Energy Alternative Fuels Data Center, January 2017). Currently, a total of 18 "modern" DCFC stations are publically accessible in Colorado. A modern DCFC station is defined in this work as a station with at least one CHAdeMO plug and at least one SAE Combo Charging System plug. This definition excludes the Tesla Supercharger network and its proprietary DCFC plugs on the grounds that future public investments in DCFC infrastructure would support the broadest possible set of BEVs.

The last five networks (labeled as Scenarios 1-5) each represent a unique hypothetical expansion of the existing DCFC network. Each scenario uses some combination of locations from NREL's DCFC siting algorithm and CDOT's 2016 submission to the Federal Highway Administration for Alternative Fuel Corridor Designation under the FAST Act (which included 31 stations along Colorado Interstates and 47 stations along other Colorado highways) (CDOT 2016). NREL's DCFC siting algorithm was run three times, once each for Scenarios 1, 3, and 5. Each of these 
runs sited 50 "traffic-based" stations around existing and predetermined interstate and highway stations to maximize traffic exposure.

Scenarios 1 through 5 represent total DCFC station counts between 49 and 146, all below the previously calculated estimate of 204 stations by 2030. Consequently, each of these scenarios could be considered a relatively near-term ( $<10$ years) infrastructure investment scenarios for supporting PEV adoption goals specified by the Colorado Energy Office.

Table 2. Hypothetical DCFC Networks Developed for BLAST-V Simulation-Based Evaluations

\begin{tabular}{|c|c|c|}
\hline Name & $\begin{array}{l}\text { Total DCFC } \\
\text { Stations }\end{array}$ & Notes \\
\hline Baseline & 0 & No stations \\
\hline Existing & 18 & Existing (per Alternative Fuels Data Center) \\
\hline Scenario 1 & 68 & Existing plus 50 "traffic-based" stations \\
\hline Scenario 2 & 49 & $\begin{array}{l}\text { Existing plus } 31 \text { interstate stations (based on CDOT FAST Act } \\
\text { proposal) }\end{array}$ \\
\hline Scenario 3 & 99 & $\begin{array}{l}\text { Existing plus } 31 \text { interstate stations (based on CDOT FAST Act } \\
\text { proposal) plus } 50 \text { "traffic-based stations" }\end{array}$ \\
\hline Scenario 4 & 96 & $\begin{array}{l}\text { Existing plus } 31 \text { interstate stations plus } 47 \text { highway stations (based } \\
\text { on CDOT FAST Act proposal) }\end{array}$ \\
\hline Scenario 5 & 146 & $\begin{array}{l}\text { Existing plus } 31 \text { interstate stations plus } 47 \text { highway stations (based } \\
\text { on CDOT FAST Act proposal) plus } 50 \text { "traffic-based stations" }\end{array}$ \\
\hline
\end{tabular}

The hypothetical DCFC networks developed for simulation-based evaluation using BLAST-V are shown in Figures 6 through 11 (overlaid with locations for the top 6 Colorado airports and 26 ski resorts, intended to represent popular destinations for long-distance travel). While the simulation-based evaluation requires specification of exact station coordinates (for resolving spatial/temporal consumer demand for DCFC), these locations are meant to represent a set of hypothetical DCFC networks and are not being proposed as actual sites for new DCFC station installations. A number of factors for exact location siting have been omitted in this analysis, including proximity to appropriately sized electrical infrastructure, land use and ownership, and parking availability. While these factors have not been addressed, the hypothetical networks shown here are meant to be illustrative in terms of what future DCFC networks could look like in terms of volume and spacing of DCFC stations. For estimating capital and operating expenditures associated with each of these hypothetical networks, readers are referred to a report led by the City and County of Denver, Denver's Opportunity for Vehicle Electrification: Overcoming Charging Challenges to Maximize Air Quality Benefits (Department Environmental Health, City and County of Denver, forthcoming), and an Idaho National Laboratory report, Considerations for Corridor and Community DC Fast Charging Complex System Design (Francfort et al. 2017). 


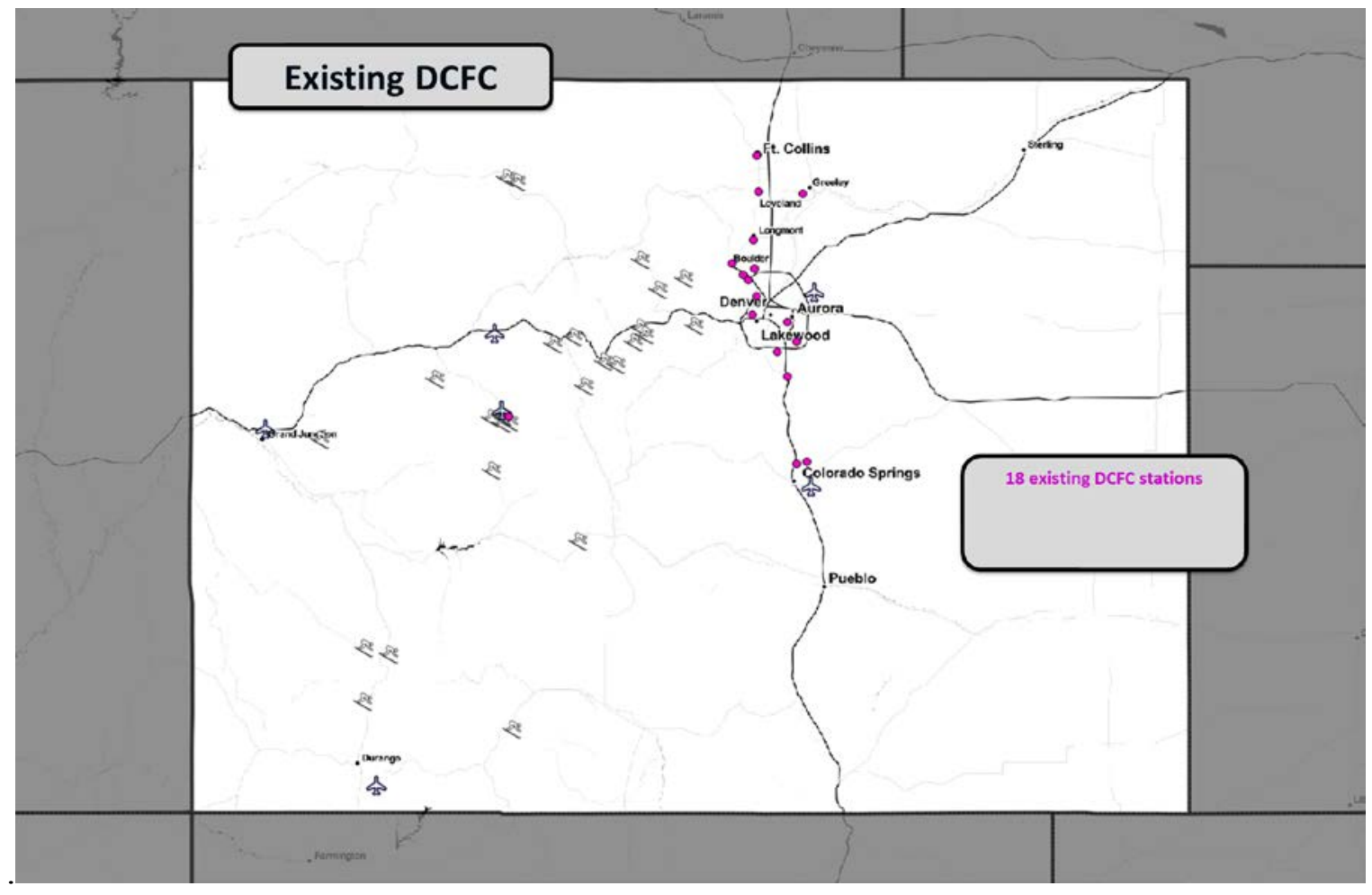

Figure 6. Existing scenario: Colorado's existing 18 DCFC stations

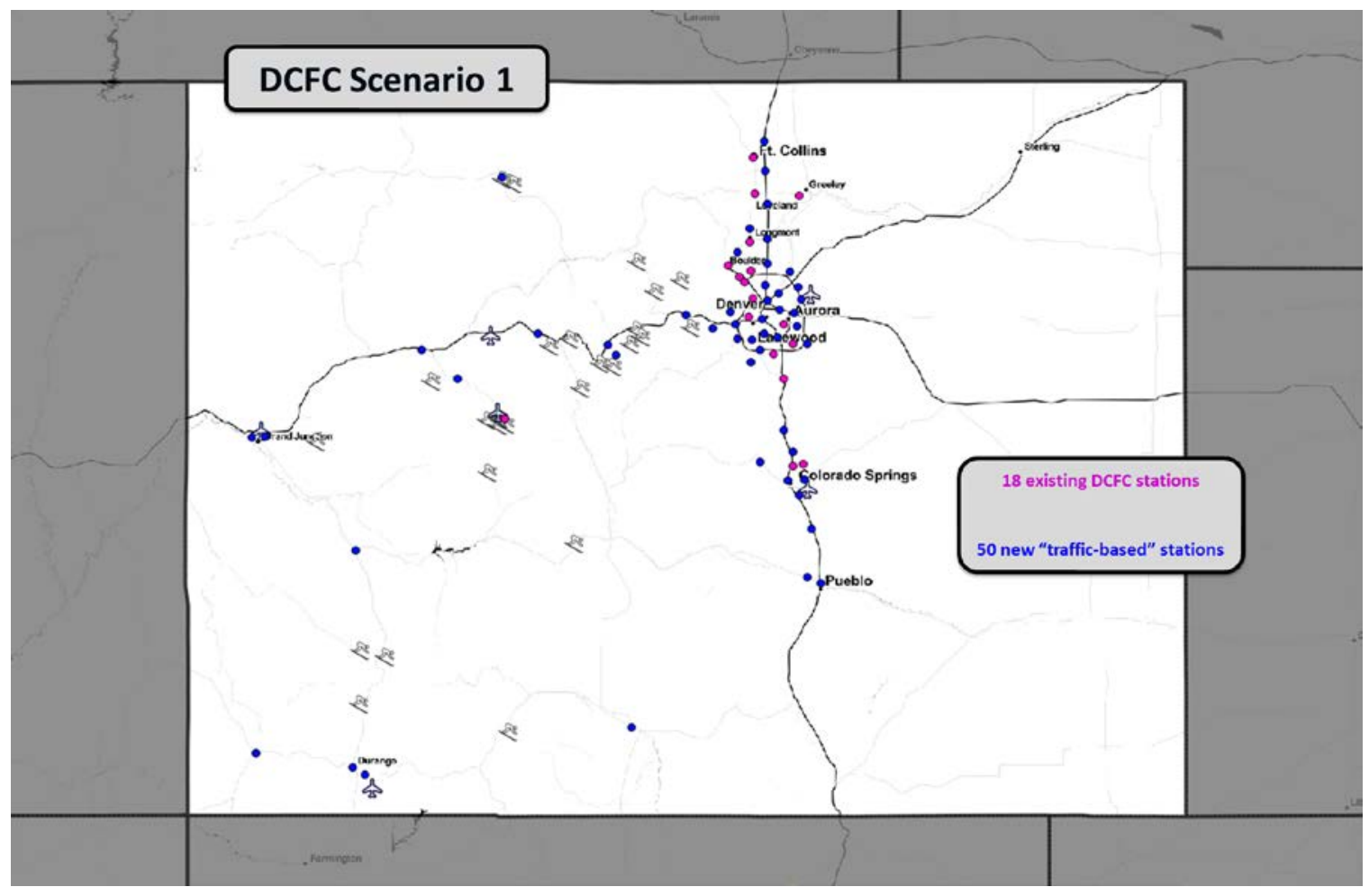

Figure 7. Scenario 1: Colorado's existing 18 DCFC stations plus 50 stations sited by NREL algorithm (68 total stations) 


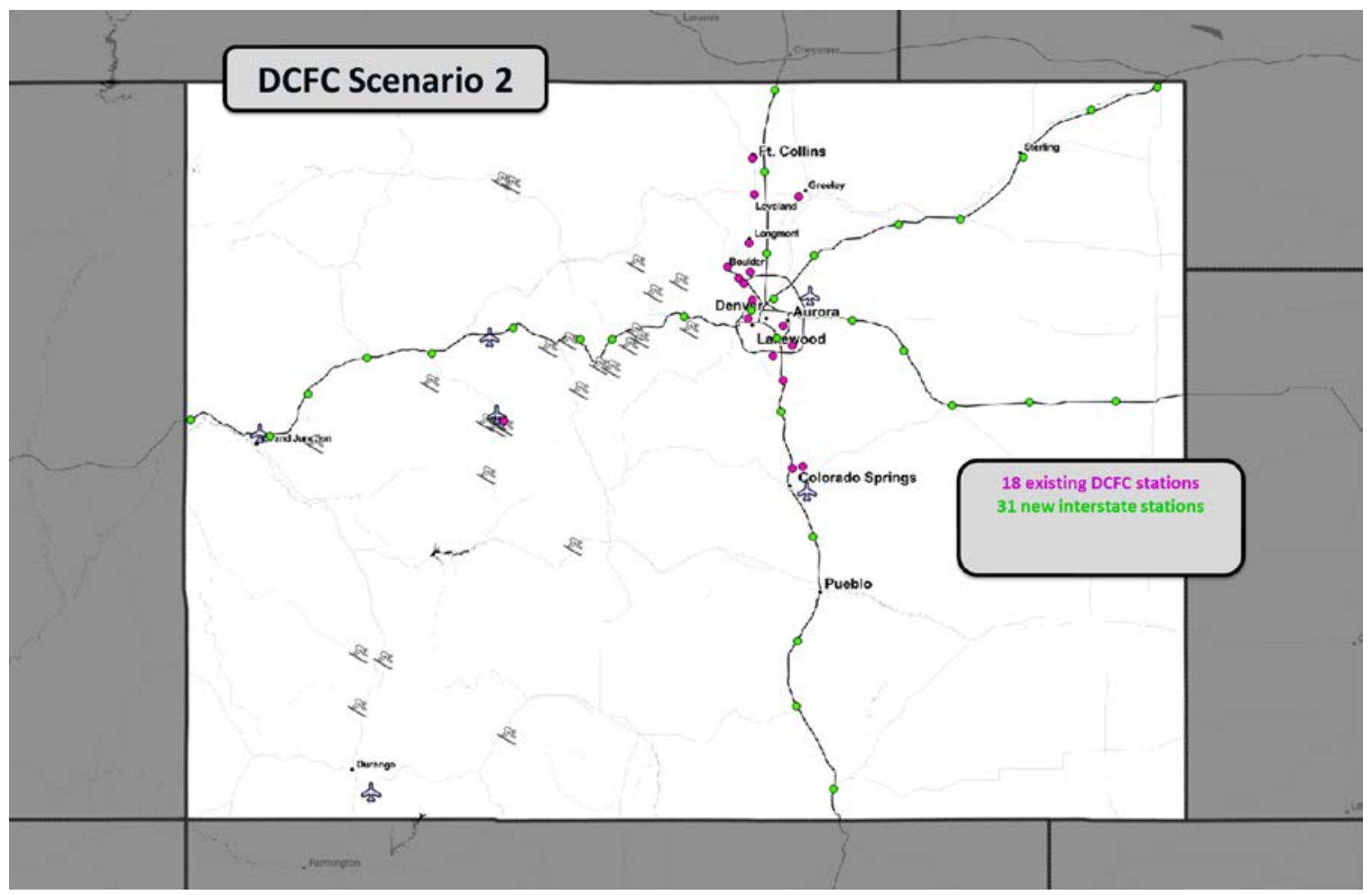

Figure 8. Scenario 2: Colorado's existing 18 DCFC stations plus 31 Interstate stations (49 total stations)

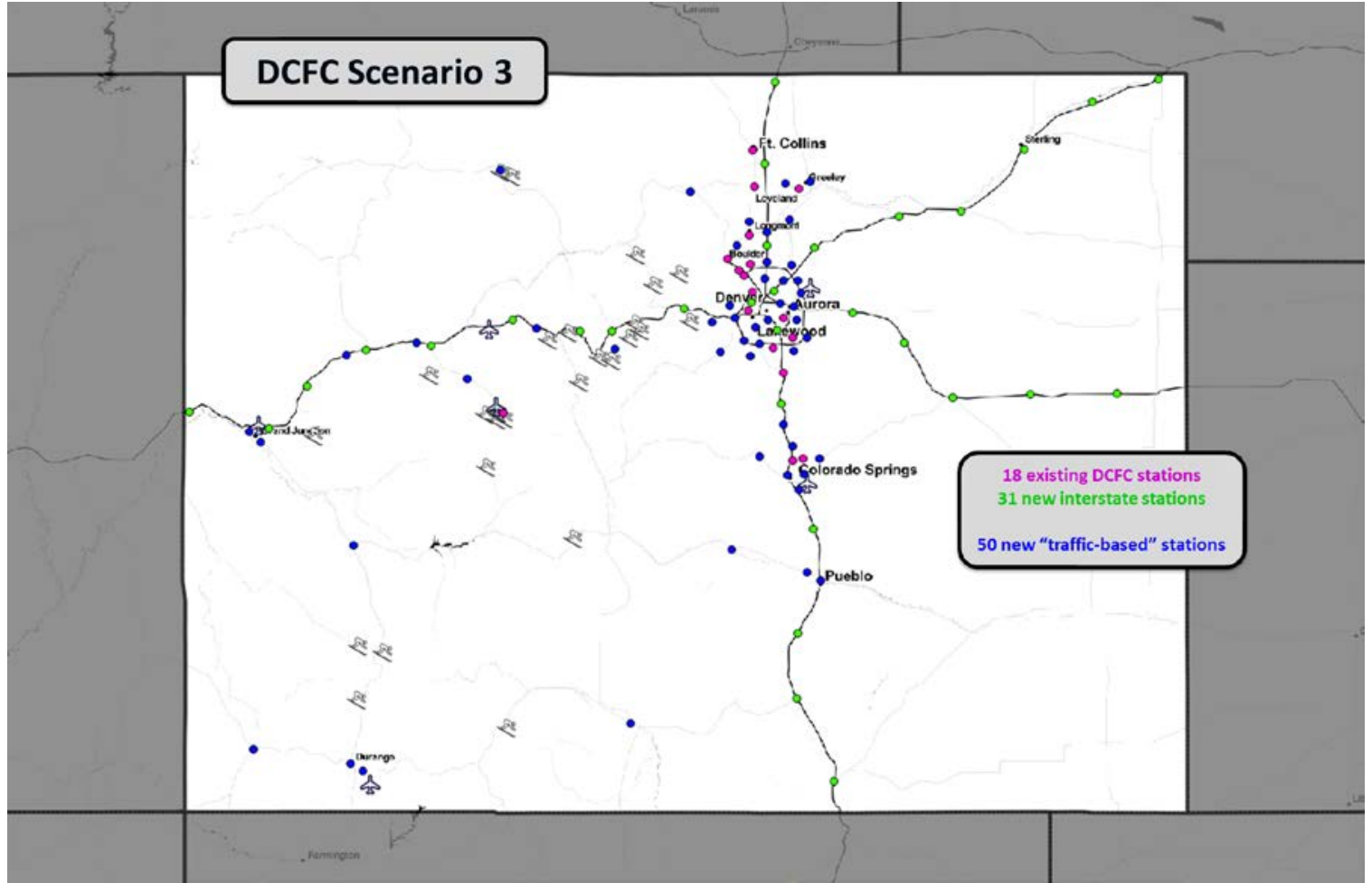

Figure 9. Scenario 3: Colorado's existing 18 DCFC stations plus 31 Interstate stations plus 50 stations sited by NREL algorithm (99 total stations) 


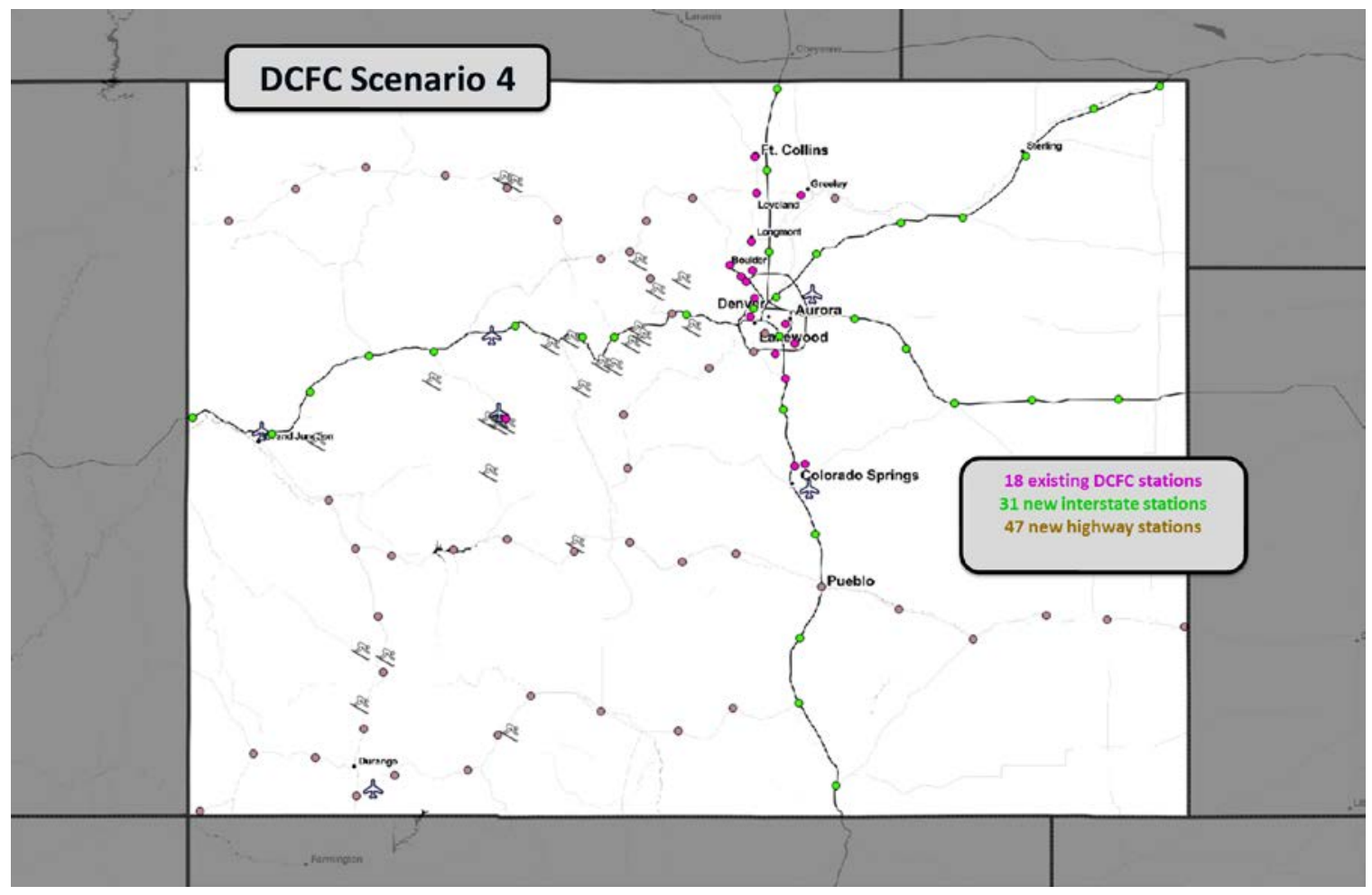

Figure 10. Scenario 4: Colorado's existing 18 DCFC stations plus 31 Interstate stations plus 47 highway stations (96 total stations)

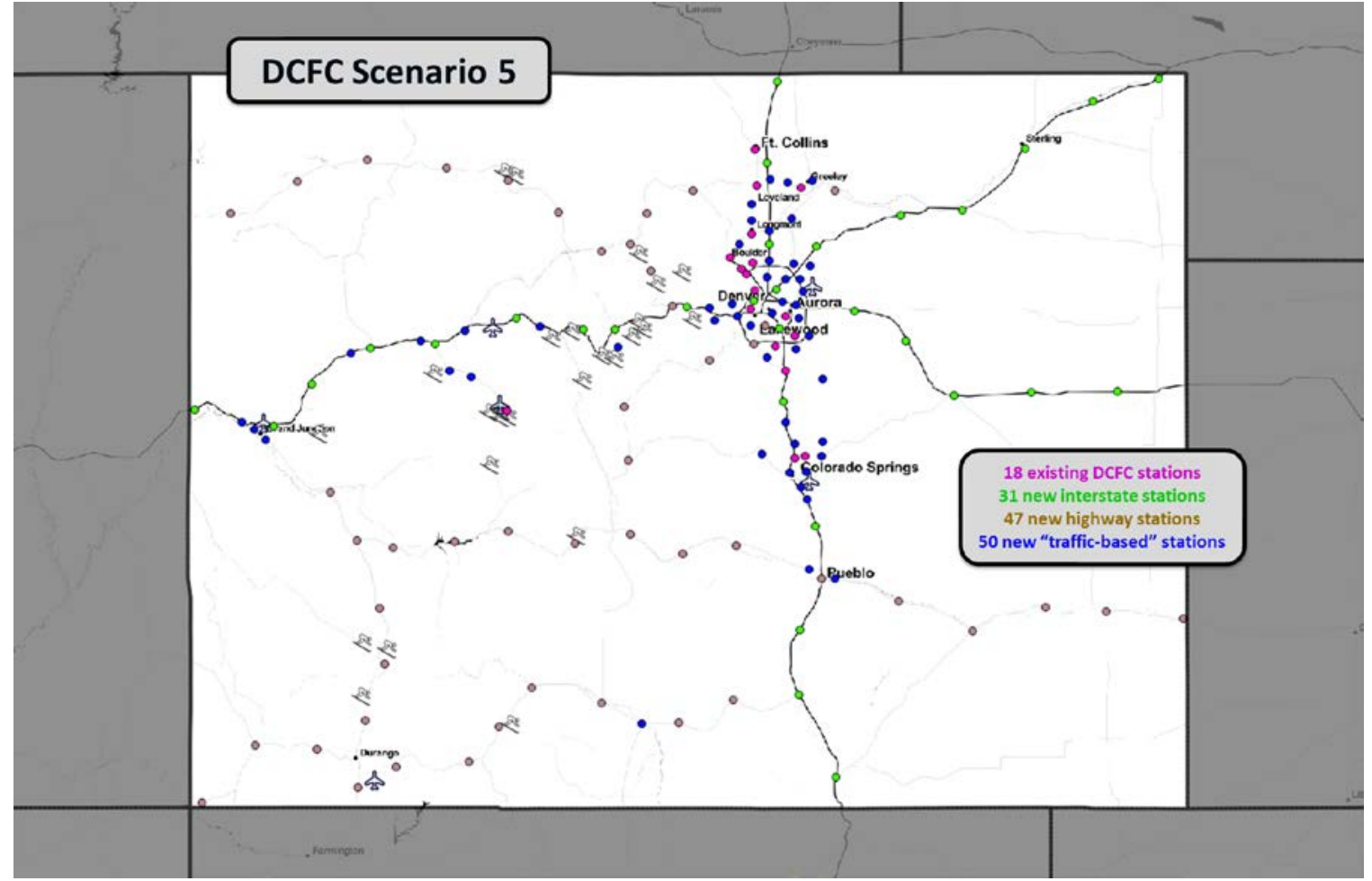

Figure 11. Scenario 5: Colorado's existing 18 DCFC stations plus 31 Interstate stations plus 47 highway stations plus 50 stations sited by NREL algorithm (146 total stations) 


\section{Front Range Travel Counts Household Survey}

Simulation-based evaluations of the aforementioned hypothetical DCFC networks were conducted using NREL's BLAST-V model. BLAST-V is a bottom-up, time series simulator of electric vehicles and requires empirical travel data describing individual vehicle movements as a primary input (typically from conventional gasoline vehicles with no range constraint, which are then simulated as electric vehicles). This analysis relies on data from the FRTC survey to quantify existing consumer driving behavior in Colorado. It is important to note that the FRTC survey only includes weekday travel data and is not able to model weekend recreational driving.

The FRTC data are from a composite travel survey administered by the four Front Range metropolitan planning organizations: North Front Range Metropolitan Planning Organization, Denver Regional Council of Governments, Pikes Peak Area Council of Governments, and Pueblo Area Council of Governments. The FRTC survey was administered in 2010 and includes a single weekday of travel for all households surveyed (weekend travel was not included). A total of 12,385 households, 17,159 vehicles, 88,201 driving trips, and 524,748 driving miles are included in the FRTC data (following NREL processing to isolate for only vehicles making at least one trip on the survey day). For each FRTC household, all vehicle trips are surveyed with trip start time, end time, destination type (e.g., home, work, school, etc.), and census block of destination recorded. A map of all vehicle trip destinations (by census block) is shown in Figure 12 , and a breakdown of vehicle counts by region is shown in Table 2.

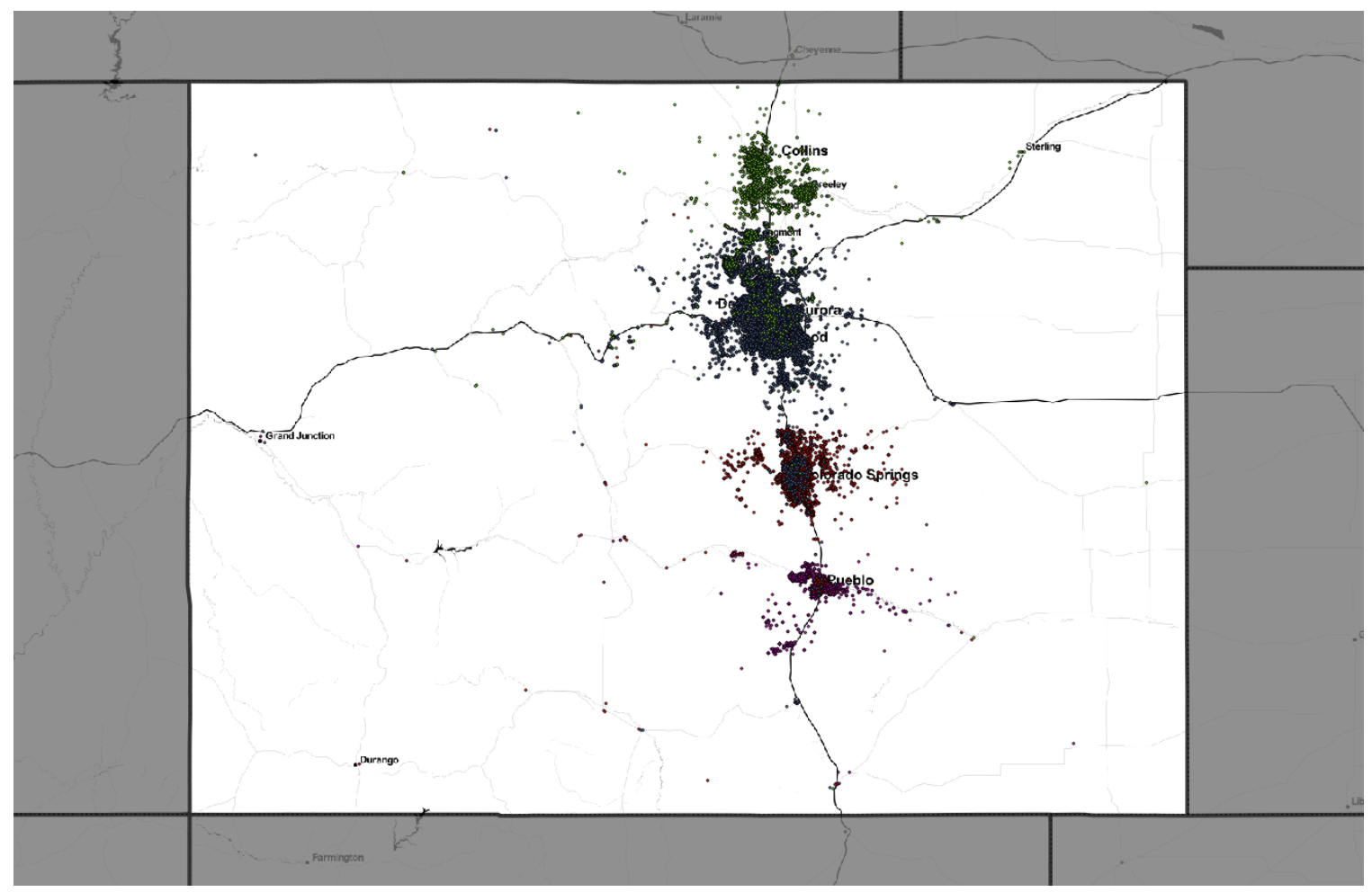

Figure 12. FRTC survey trip destinations (personal car only) 
Table 3. Vehicle Counts by Metropolitan Planning Organization from the Front Range Travel Counts Survey

\begin{tabular}{ll}
\hline Metropolitan Planning Organization & Vehicle Count \\
\hline North Front Range Metropolitan Planning Org & 2,168 \\
\hline Denver Regional Council of Governments & 9,756 \\
\hline Pikes Peak Area Council of Governments & 3,846 \\
\hline Pueblo Area Council of Governments & 1,389 \\
\hline Total & 17,159 \\
\hline
\end{tabular}

All FRTC origin-destination pairs were run through a web-based routing application program interface to determine likely routes driven and associated driving distances. Route alternatives from the application program interface are utilized by BLAST-V to simulate driving along paths with access to DCFC stations (when necessary and if such a path exists). An example of three route alternatives for a hypothetical origin-destination pair is shown in Figure 13 (overlaid with locations of existing DCFC stations), and a heat map of all FRTC estimated routes is shown in Figure 14.

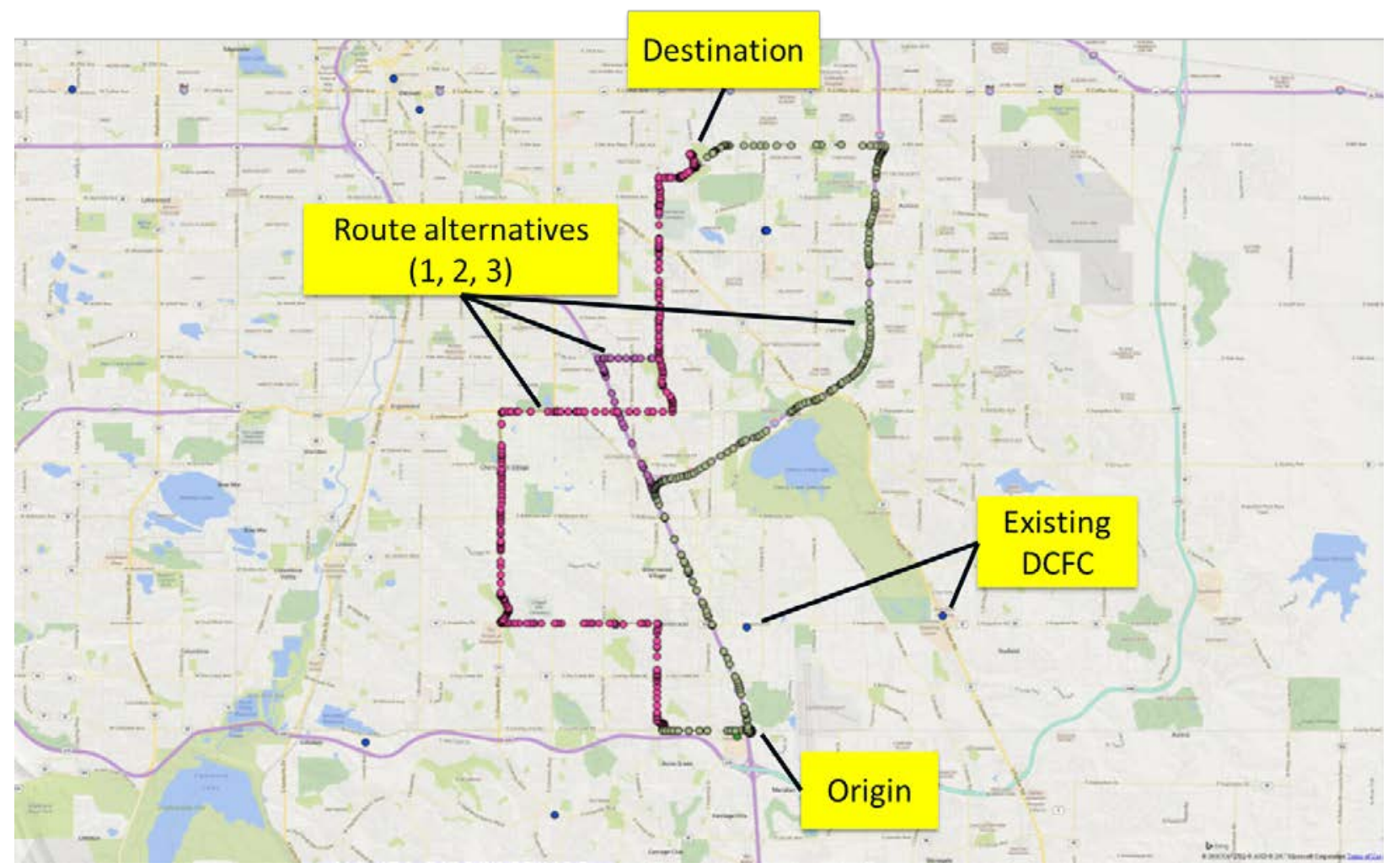

Figure 13. Hypothetical origin-destination pair with three route alternatives (overlaid with existing DCFC stations)

Map credit: @ 2009 Google, Map Data @ 2009 Tele Atlas 


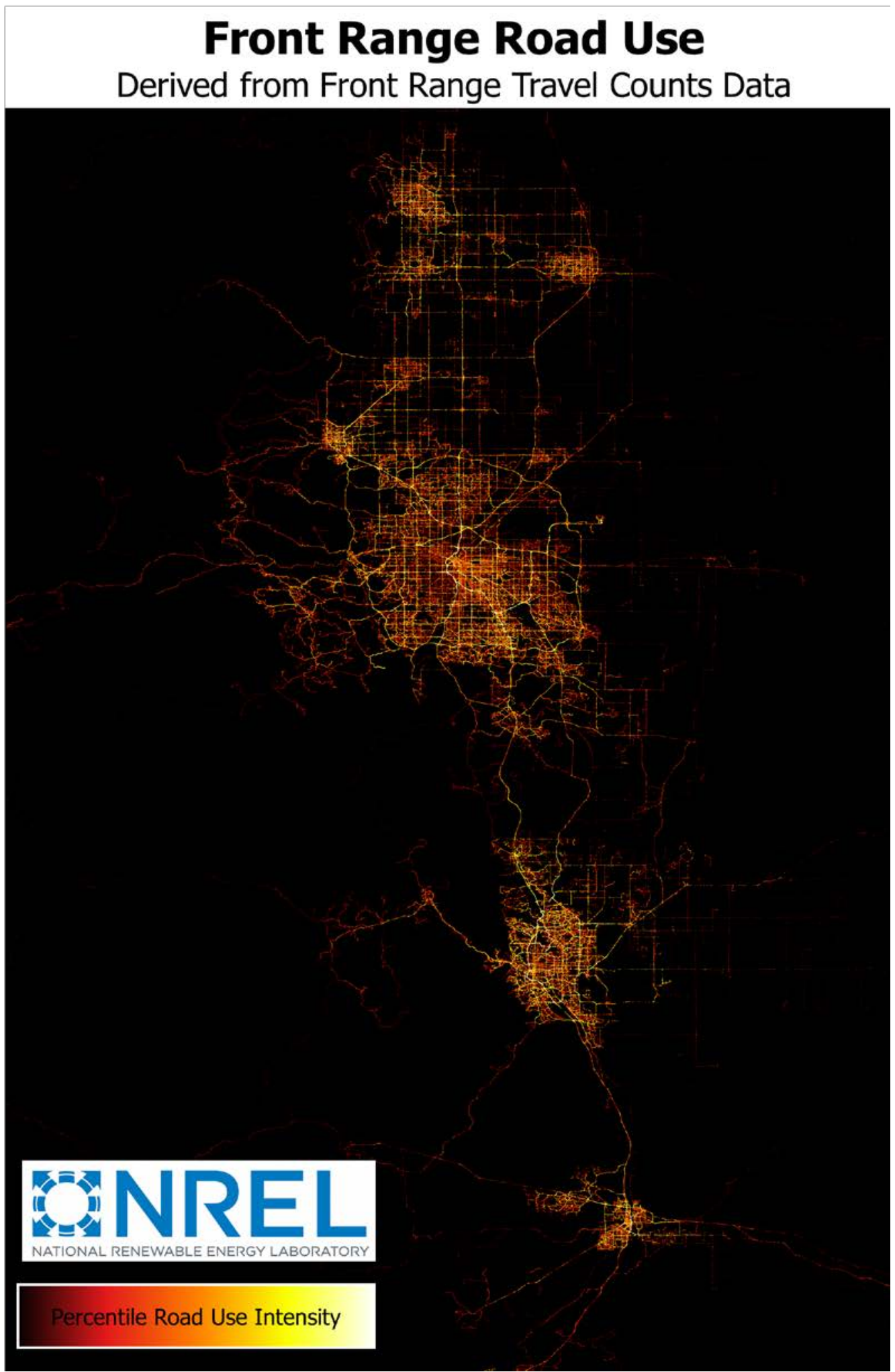

Figure 14. Heat map of FRTC estimated driving routes used in BLAST-V simulations 
Ultimately, one of the most predictive measures from a travel survey for estimating consumer DCFC demand is the distribution of daily vehicle miles traveled (VMT). Assuming access to charging at the vehicle's home location, the distribution of daily VMT provides an estimate for the percentage of driving days that are beyond the single charge range of a given BEV. The FRTC distribution of daily VMT is shown in Figure 15 (with distances derived from the top application program interface recommended route for each driving trip).

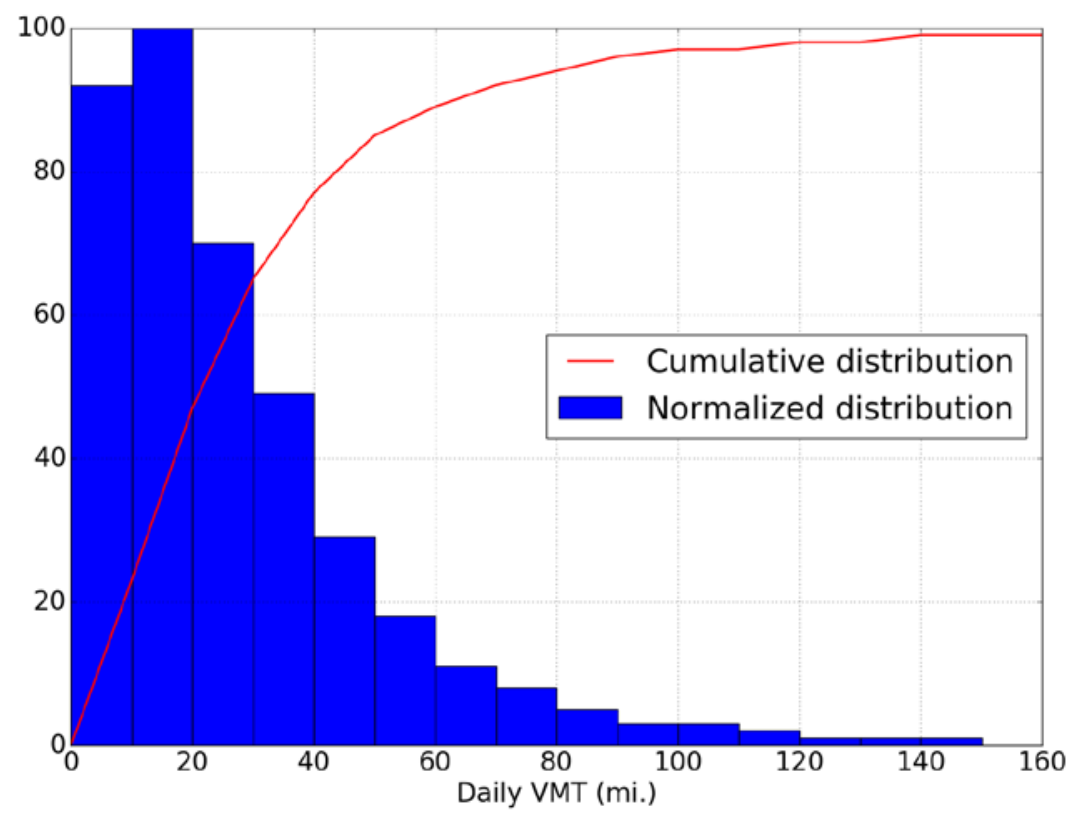

Figure 15. FRTC daily VMT distribution

The FRTC distribution of daily VMT is consistent with other regional travel surveys with a median daily VMT of approximately 20 miles and approximately $95 \%$ of vehicle days below 100 miles. Such distributions are a cornerstone of BEV advocates who emphasize the large share of driving that can be accommodated with a BEV that only has access to charging at the home location. While these daily VMT distributions make a strong argument for the ability of BEVs to satisfy the majority of consumer driving needs, consumers are notoriously cautious with respect to vehicle purchase decisions and tend to elect for utility beyond their typical needs (e.g., driving range, seating capacity, cargo capacity, towing capacity, acceleration).

Consumer access to a comprehensive network of DCFC stations would reduce the influence of range anxiety (both real and perceived) as a barrier to increased BEV sales. Results of BLAST-V simulations are presented in Section 5 to estimate the actual consumer benefits and utilization of several hypothetical DCFC networks using travel data from the FRTC survey. 


\section{BLAST-V Driving/Charging Simulations}

BLAST-V is an electric vehicle simulator focused on computing the long-term effects of complex operational scenarios on vehicle utility and battery performance. It considers the vehicle powertrain, battery control strategy, driving and charging patterns, local climate, vehicle-batteryenvironment thermal system, battery chemistry, and other factors in computing short-term vehicle and battery performance (e.g., vehicle range, battery voltage, state of charge [SOC], and temperature) and long-term vehicle utility and battery degradation. Further details on the methods employed are described in Neubauer (2014).

BLAST-V is applied to a matrix of scenarios in Colorado using the FRTC data. Specifically, models of a mid-size BEV sedan with 100, 200, and 300 miles (BEV100, BEV200, and BEV300, respectively) of nominal driving range are considered. These models are evaluated using the seven DCFC networks described in Section 3. All 21 combinations of BEV type and DCFC network are simulated both for a nominal driving range scenario and a scenario in which $\mathrm{BEV}$ driving range is compromised due to extreme ambient conditions and the associated battery/cabin thermal management loads. Finally, BLAST-V is used to consider a scenario where a subset of consumers (those residing in homes other than single-unit dwellings [SUDs]) does not have access to home charging and is entirely reliant on a DCFC network.

\subsection{Methodology}

Determination of which trips to take with a BEV and which to forgo is key to BLAST-V. As input driving patterns are generally sourced from real-world operation of conventional gasoline vehicles, certain trips (and sequences of trips) will exceed the driving range of the simulated $\mathrm{BEV}$ and result in full battery depletion. Given the cost and inconvenience associated with stranded vehicles, BLAST-V assumes BEV drivers will rely on conservative estimates of vehicle range and detailed knowledge of travel itineraries to avoid running out of charge mid-trip.

BLAST-V structures travel data as a sequence of tours. Each tour consists of consecutive trips with the first trip beginning and the last trip ending at the vehicle's home location (with assumed access to charging). Prior to the start of each tour, BLAST-V considers the battery's current SOC, distance and expected duration of pending trips in the tour, historical depletion rates from similar trips, and availability of work/public charging stations, to estimate battery SOC throughout the potential tour.

This estimation informs a go/no-go decision at the beginning of each tour. In situations where the estimated battery SOC is not predicted to be maintained above the driver's required threshold, BLAST-V offers the capability to consider alternate paths of travel and stops at available DCFC stations, as described in Wood et al. (2015). If BLAST-V's rerouting algorithm is able to successfully identify a revised travel plan that maintains estimated battery SOC above the driver's minimum requirement, statistics on the rerouted tour are recorded (e.g., number of DCFC stops, duration of DCFC stops, incremental distance relative to original tour), and the rerouted tour is simulated in greater detail. However, if an adequate alternate tour is not identified, the driver forgoes use of the BEV, and electrical, thermal, and life models of the battery pack are simulated with the vehicle in its parked mode for the duration of the tour. 
BLAST-V's go/no-go decision for determining BEV travel is believed to mirror the way that real-world drivers make personal travel decisions. By implementing a low-order planning model prior to tour evaluation, BLAST-V simulates the tour decisions a driver makes every day when determining whether their BEV is suitable for a particular tour. While BLAST-V is not primarily concerned with alternate travel modes in situations where BEV travel is dismissed, it is reasonable to assume that real-world drivers would coordinate use of a secondary household vehicle (likely a conventional gasoline vehicle), arrange for a short-term rental vehicle, utilize some form of public transportation, plan a carpool, or potentially omit the tour entirely.

\subsection{Results}

BLAST-V simulation results are categorized into three sections: 1) baseline efficiency, 2) reduced efficiency, and 3) no home charging at multiple-unit dwellings (MUDs). Results for all 21 combinations of the three BEV types and seven DCFC networks are included in each section.

\subsubsection{Baseline Efficiency}

Simulated fleet percent eVMT results for the baseline BEV efficiency scenario are presented in Figure 16.

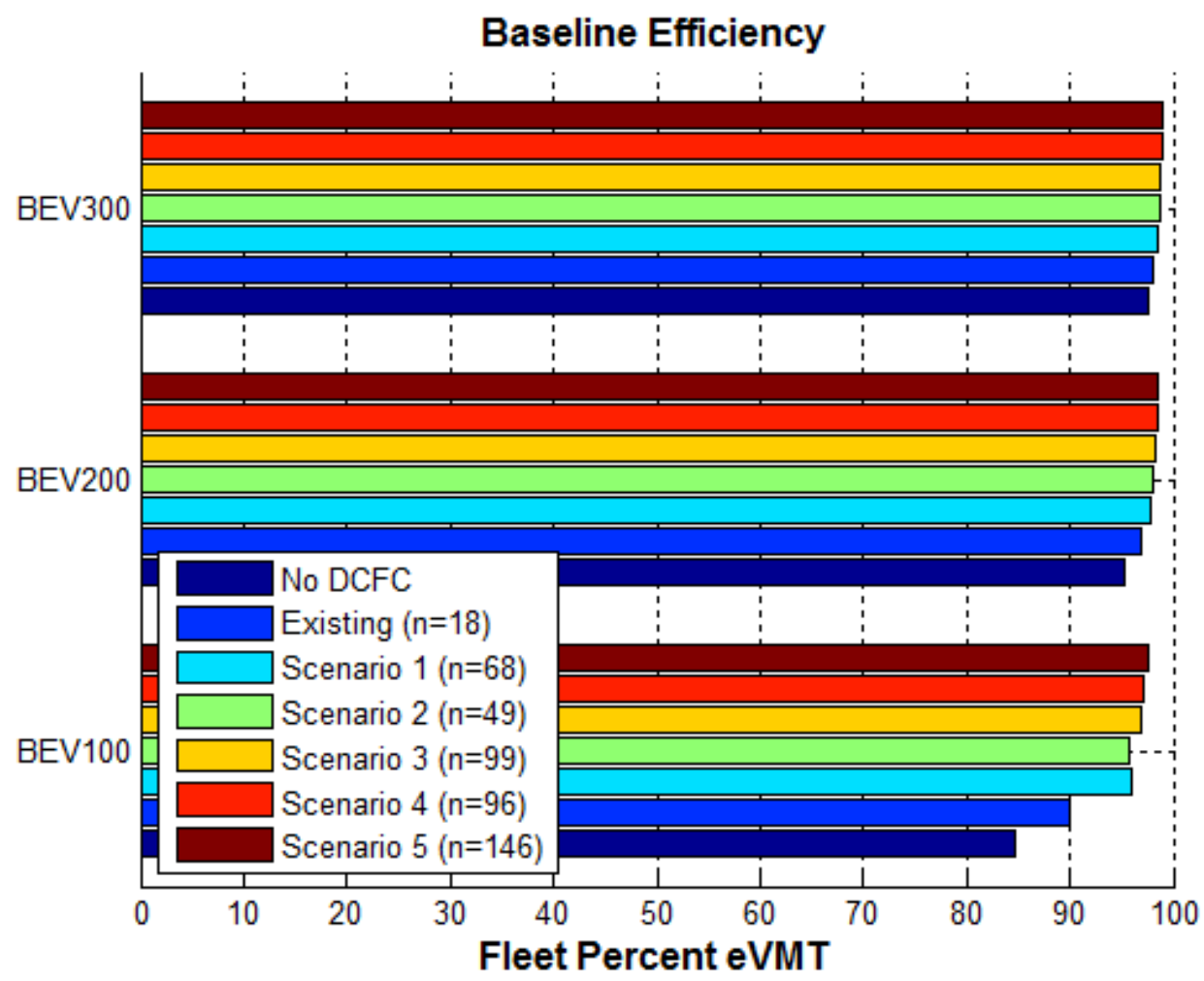

Figure 16. Simulated fleet percent eVMT by BEV type and DCFC network

The most limiting case for driving range is represented by the BEV100 paired with no DCFC stations. In this case, the simulated fleet of consumers is able to achieve approximately $85 \%$ of their desired daily VMT. BEV100 consumers are shown to benefit from increased access to DCFC stations, albeit with diminishing returns as the most critical charging locations are covered in the early DCFC scenarios. The incremental benefit of moving from 18 stations in the existing 
scenario to 68 stations in Scenario 1 is approximately 5 percentage points in eVMT improvement, while moving from 68 stations in Scenario 1 to 146 stations in Scenario 5 is approximately 2 percentage points. Similar trends are observed for the BEV200 and BEV300, which each start from higher eVMT baselines. In the case of the BEV300 with the support of 146 DCFC stations, fleet percent eVMT reaches approximately $99 \%$ with the remaining uncovered miles comprising out of state travel, which is not considered in any DCFC scenario. While home charging is shown capable of providing the majority of charging for the average simulated consumer, the value of a robust DCFC network should not be understated as it provides value beyond the eVMT values estimated here (e.g. emergency charging, mitigation of range anxiety).

Simulated utilization of the average DCFC station is also sensitive to the mix of vehicles on the road and the density of DCFC stations. Figure 17 shows simulated DCFC utilization in terms of average daily charge events per station per 1,000 BEVs. The simulated BEV100 is clearly the most reliant of the three BEV types on a DCFC network. For the existing network of 18 DCFC stations, the simulated BEV100 results in approximately one charge event per day at the average DCFC station. While the overall utilization of the DCFC network increases with more stations, utilization of the average station in the network decreases as coverage improves and the network begins to saturate.

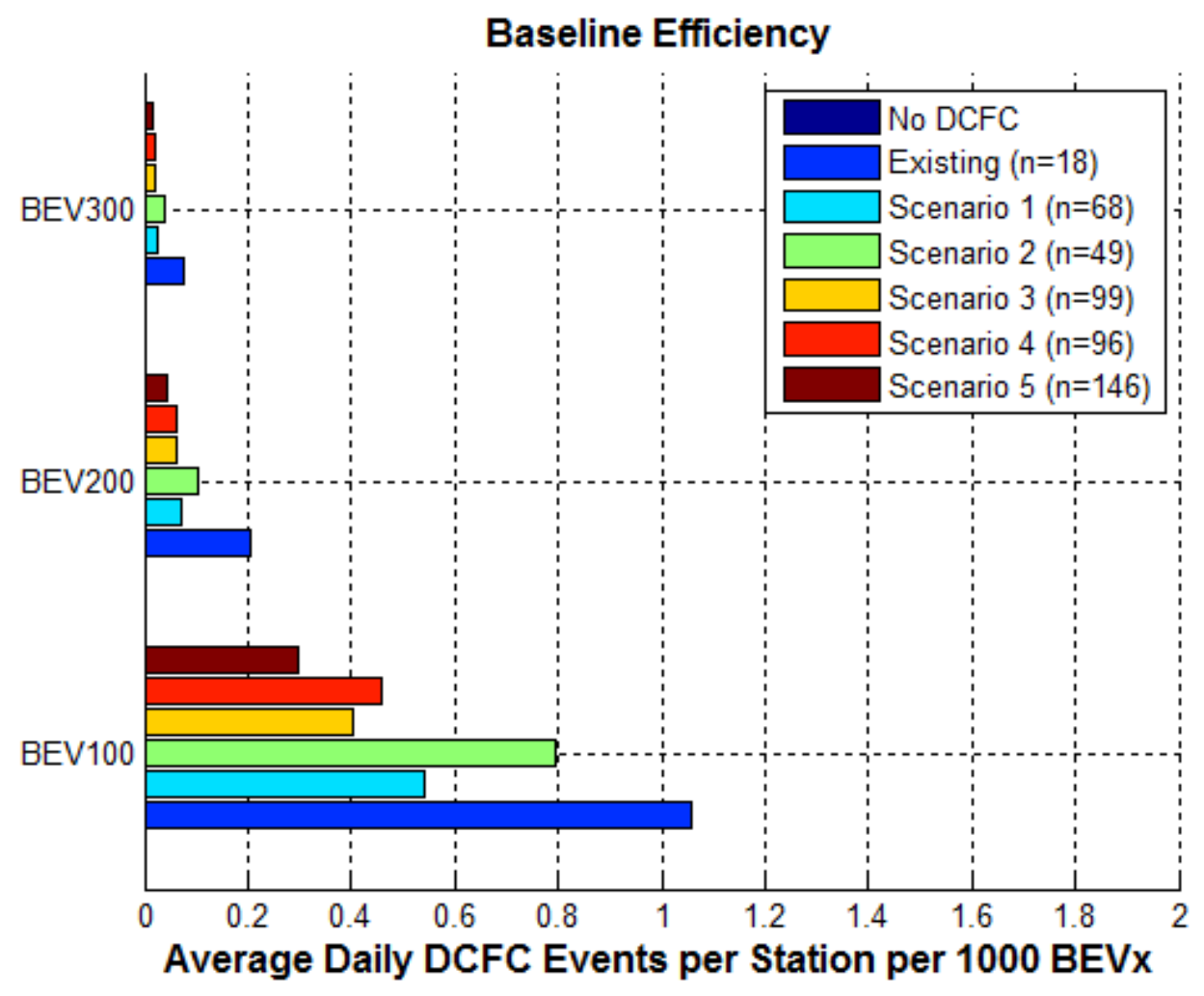

Figure 17. Simulated DCFC station utilization by BEV type and DCFC network

While average utilization is a valuable indicator of aggregate DCFC demand, it is important to note that significant spatial variability exists between individual station locations in all of the simulated networks. Figures 18 through 23 show statewide maps of station utilization by the BEV100 for the six hypothetical DCFC networks studied (the "no DCFC" network is excluded). These maps include markers at each DCFC location with the size of the marker proportional to 
the total number of simulated charge events at each station. Please note that each map is only relative to itself and that comparisons between maps on an absolute basis carry no meaning (e.g., similarly sized markers in two different maps do not imply similar utilization, only that those stations had similar relative utilization in their respective scenarios).

The primary takeaway from this set of maps is the importance of a reliable DCFC network along the I-25 corridor between Fort Collins and Pueblo for supporting inter-city travel in a BEV100. While there is some amount of simulated utilization for stations along alternative corridors and stations within the Denver metropolitan area, the I-25 corridor stands out in all six scenarios. Given knowledge of regional travel patterns and knowing that a large percentage of routine daily travel can be accommodated by a BEV100 simply with home charging, this result is perhaps intuitive. However, it is worth recalling the limitations of the FRTC data, namely, the fact that it was a weekday survey that omitted weekend recreational travel from the Front Range west into the Rocky Mountains. So while BLAST-V was unable to demonstrate high levels of DCFC demand on the highways linking the Front Range to the Rocky Mountains, the importance of enabling this weekend recreational travel should not be overlooked. Also recall that the FRTC omits households from the large rural areas of Colorado, including the Western Slope and Eastern Plains. While it is likely that the majority of BEV adoption will take place in the densely populated communities along the Front Range, DCFC connectivity for the rural parts of the Colorado should remain a priority. Finally, recall that no weighting of the FRTC data was conducted to account for future spatial variation in BEV adoption, potentially affecting these estimates of utilization by location.

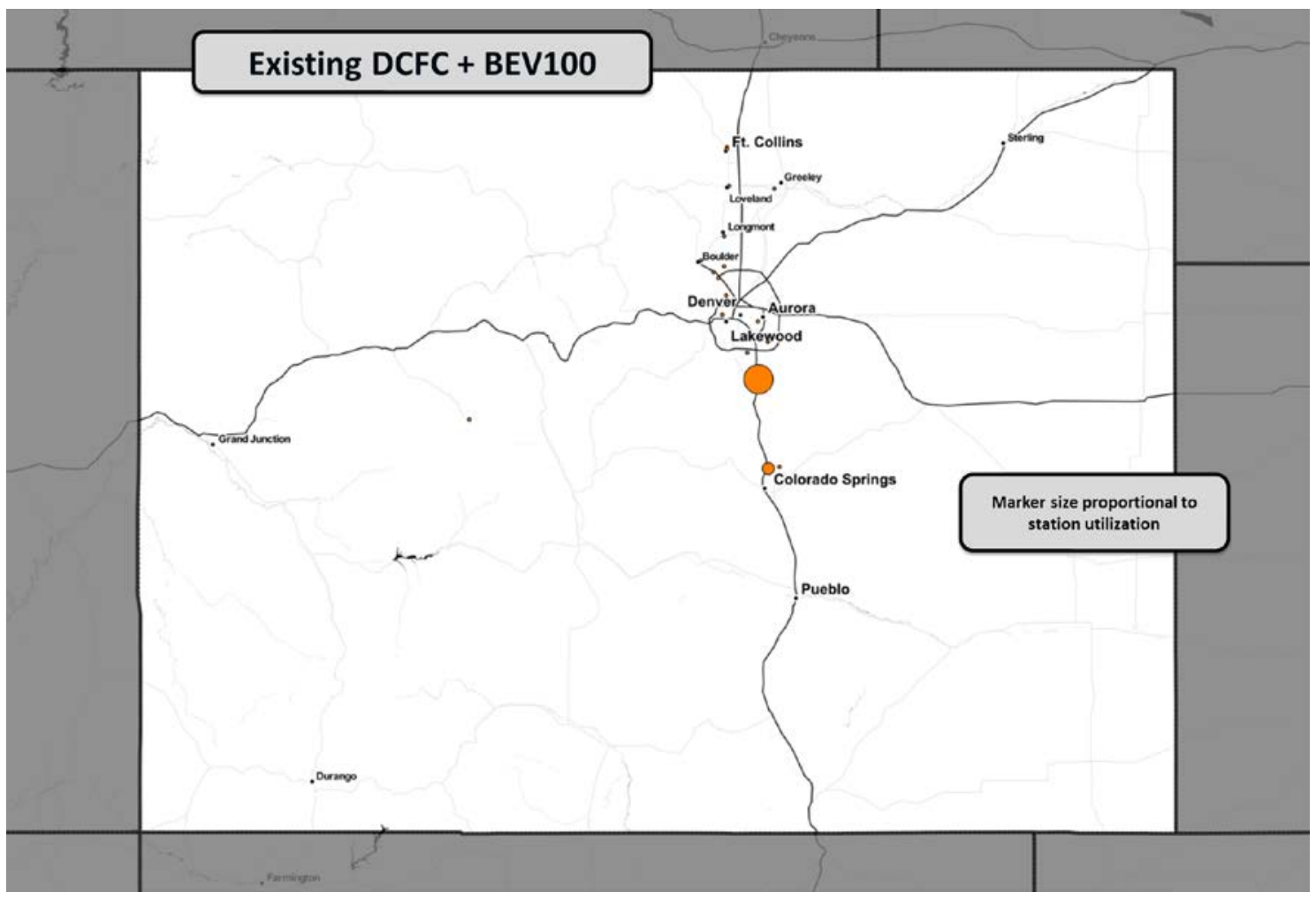

Figure 18. Simulated DCFC station utilization, marker size proportional to station charge events (BEV100, existing stations, and baseline efficiency) 


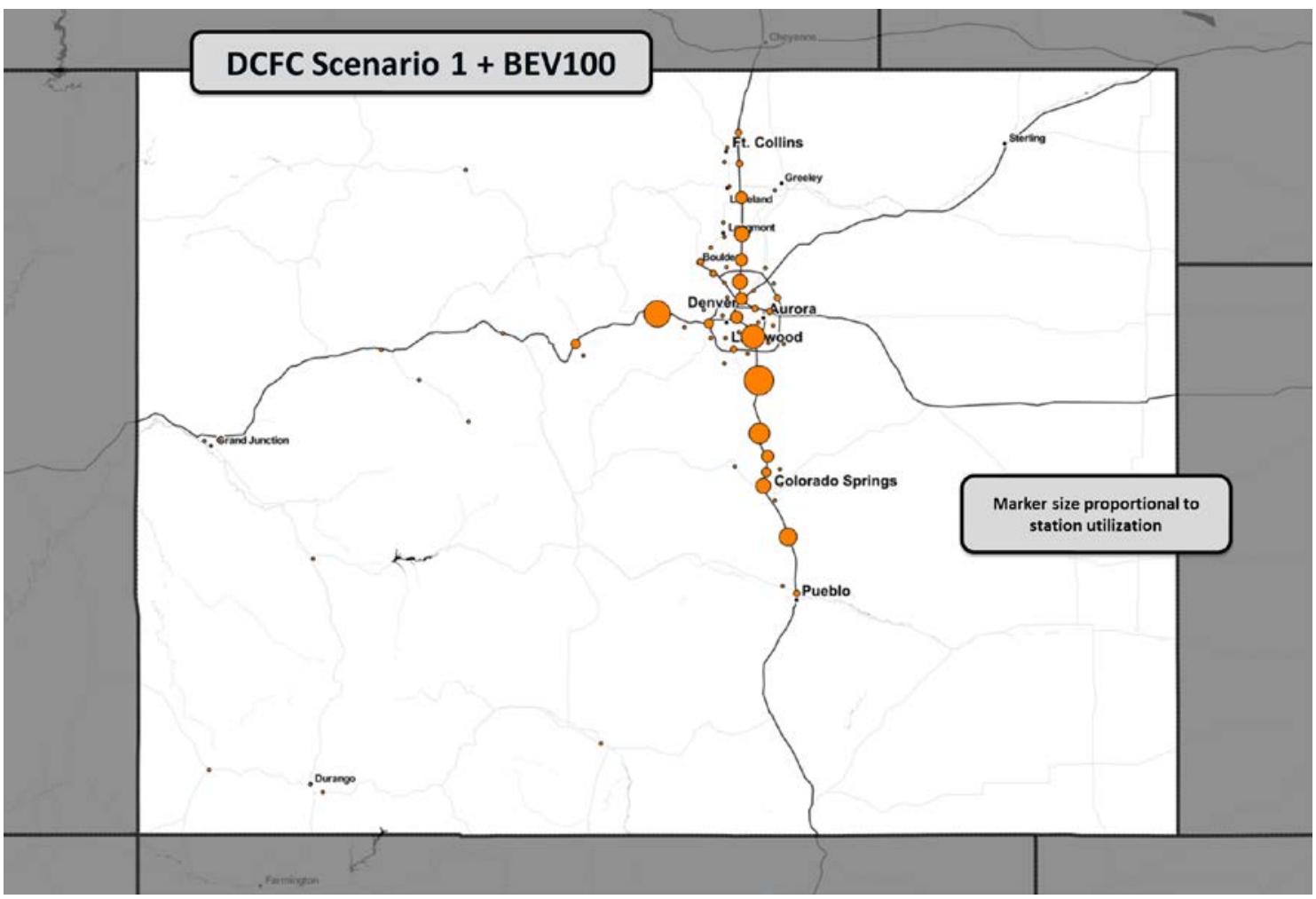

Figure 19. Simulated DCFC station utilization, marker size proportional to station charge events (BEV100, DCFC Scenario 1, and baseline efficiency)

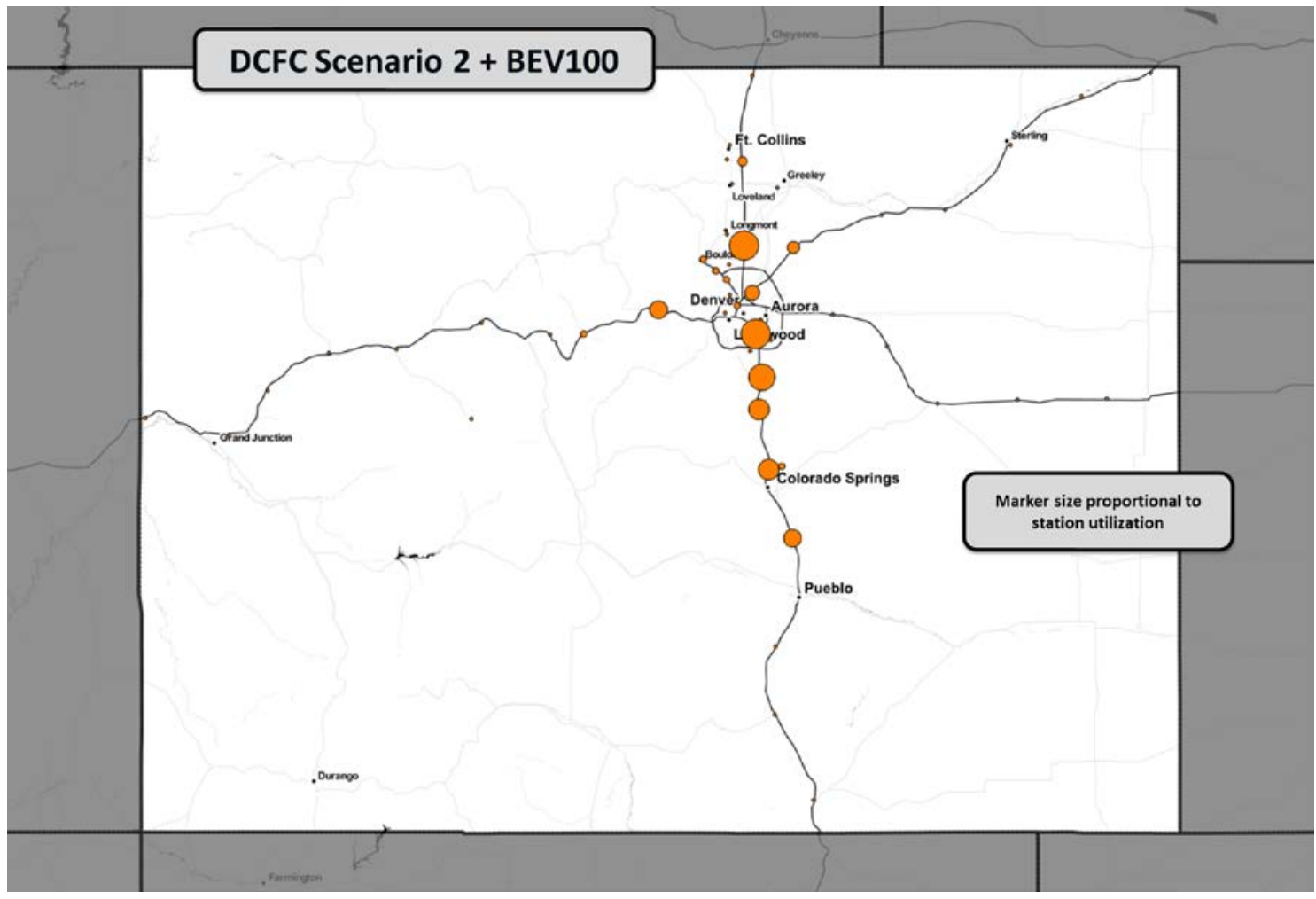

Figure 20. Simulated DCFC station utilization, marker size proportional to station charge events (BEV100, DCFC Scenario 2, and baseline efficiency) 


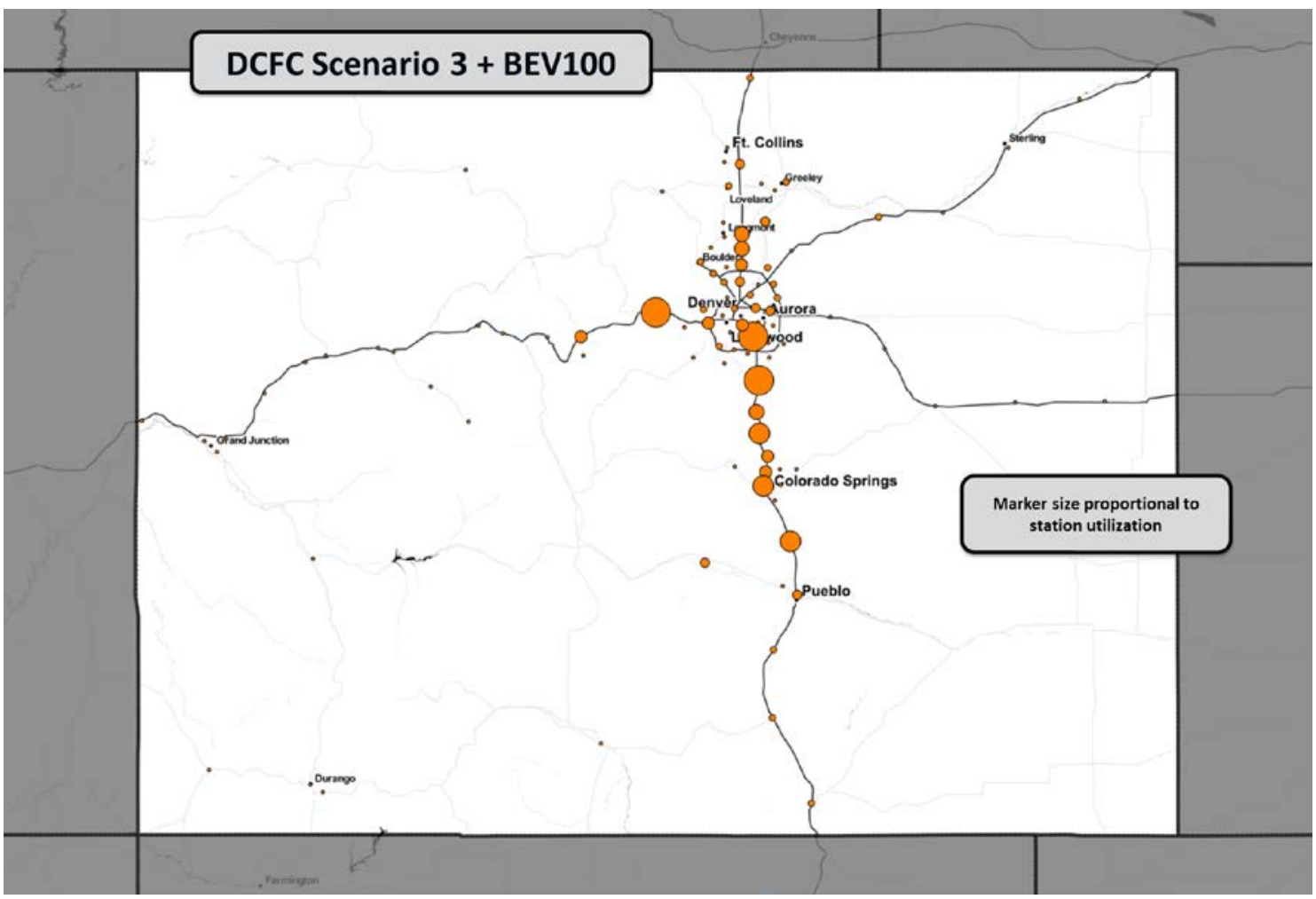

Figure 21. Simulated DCFC station utilization, marker size proportional to station charge events (BEV100, DCFC Scenario 3, and baseline efficiency)

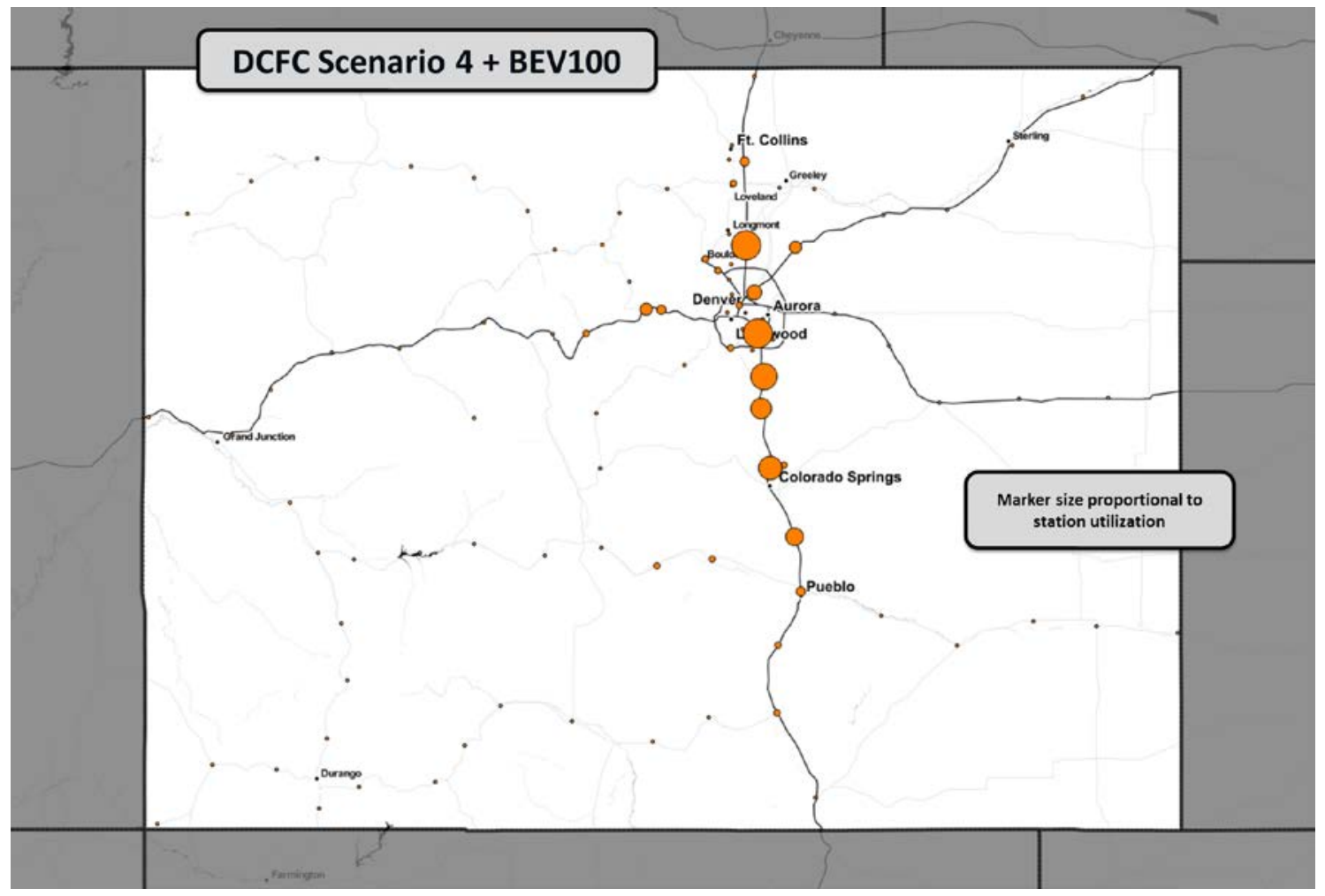

Figure 22. Simulated DCFC station utilization, marker size proportional to station charge events (BEV100, DCFC Scenario 4, and baseline efficiency) 


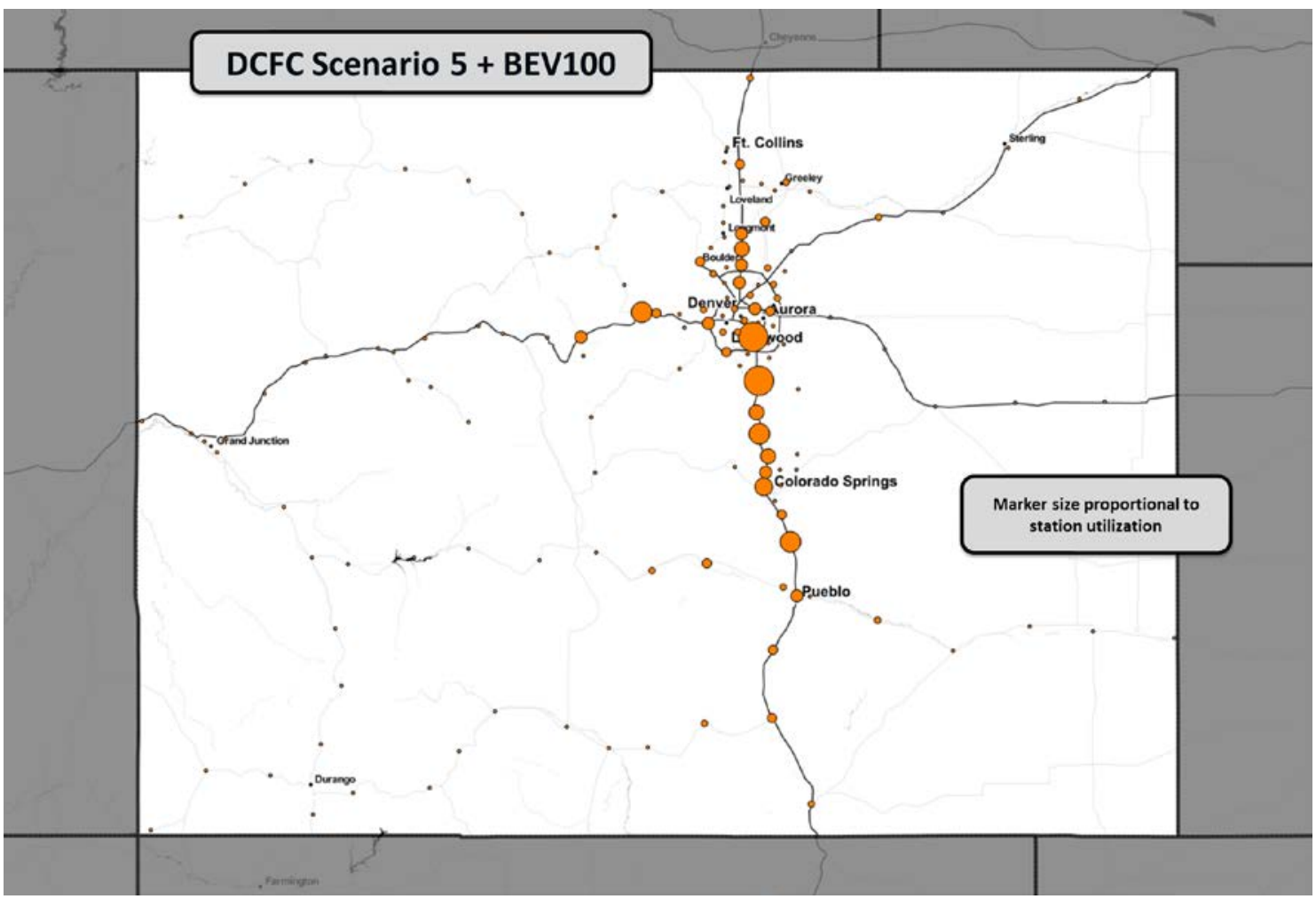

Figure 23. Simulated DCFC station utilization, marker size proportional to station charge events (BEV100, DCFC Scenario 5, and baseline efficiency)

Simulated station utilization maps for the BEV200 and BEV300 are shown in Figures 24 and 25, respectively, under the most extensive network, DCFC Scenario 5 (the BEV100 version of this map is shown in Figure 23). The primary conclusion from these maps is that the spatial utilization of DCFC stations pushes further and further away from the home locations as the single charge range of the BEV increases from 100 to 200 to 300 miles. As discussed, DCFC relative utilization for the simulated BEV100 was primarily concentrated along the Front Range. Relative utilization shifts more heavily towards outlying areas for the BEV300, which begins to see appreciable DCFC utilization on the western end of US-40 near the Utah border, along US-160 in southern Colorado, and on the eastern end of I-70 near the Kansas border. 


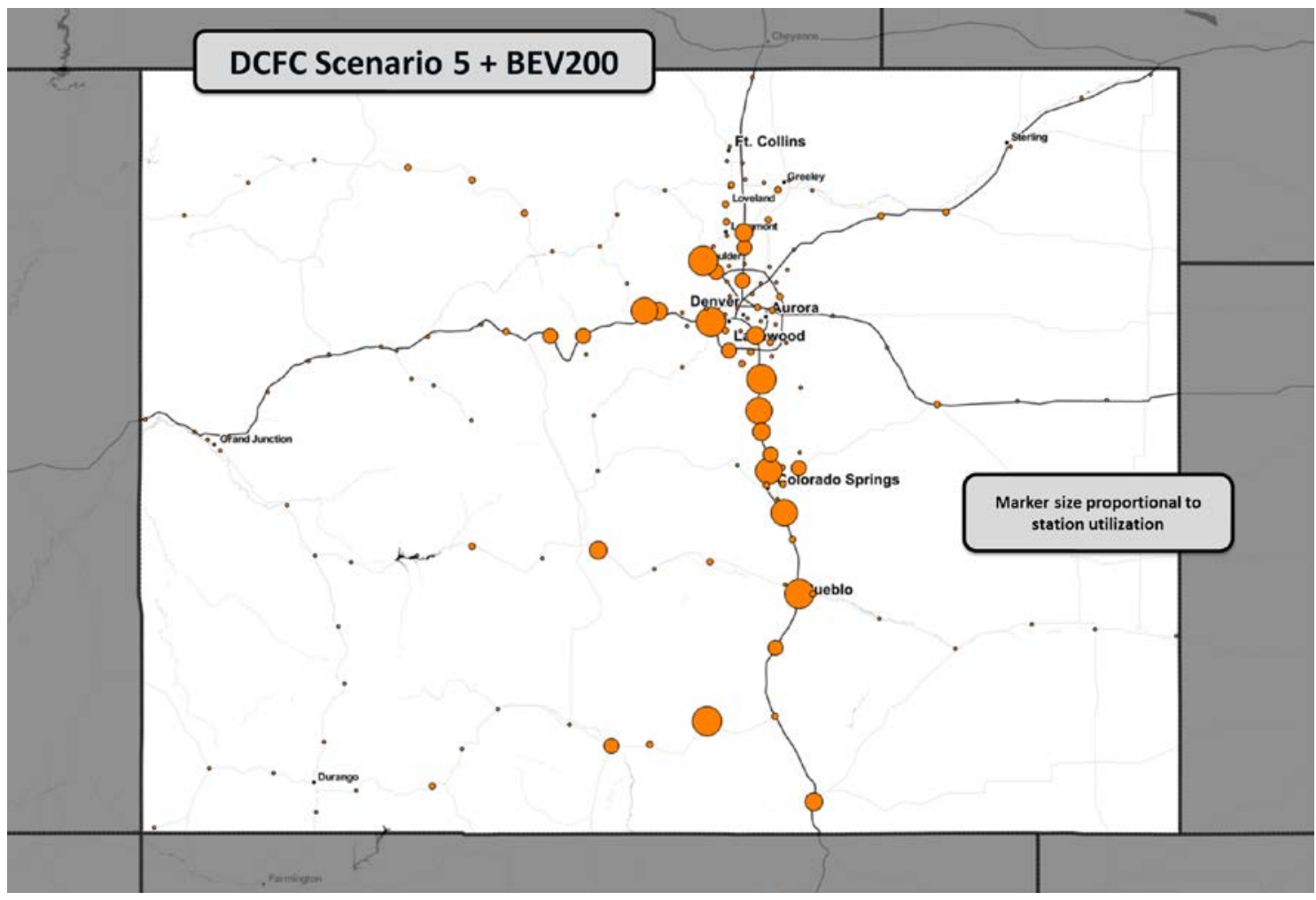

Figure 24. Simulated DCFC station utilization, marker size proportional to station charge events (BEV200, DCFC Scenario 5, and baseline efficiency)

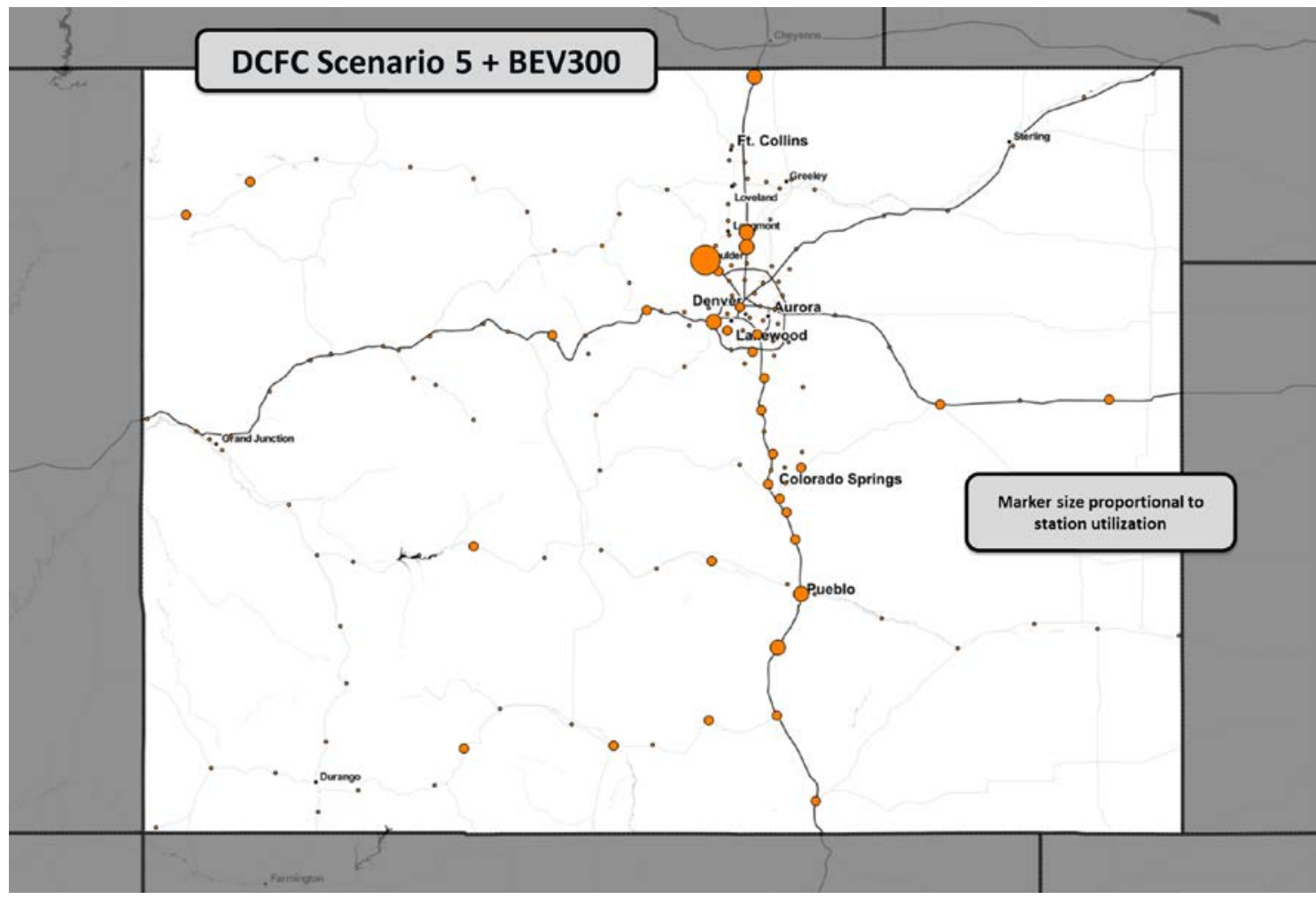

Figure 25. Simulated DCFC station utilization, marker size proportional to station charge events (BEV300, DCFC Scenario 5, and baseline efficiency) 
Simulated charging load by time of day at the average DCFC station is shown in Figure 26 for the BEV100 for DCFC Scenario 5. DCFC stations are simulated as being used most heavily between approximately 3 p.m. and 6 p.m. (likely coinciding with peak demand for travel and electricity generation). This result is consistent with real-world DCFC usage behavior observed by Idaho National Laboratory (2015).

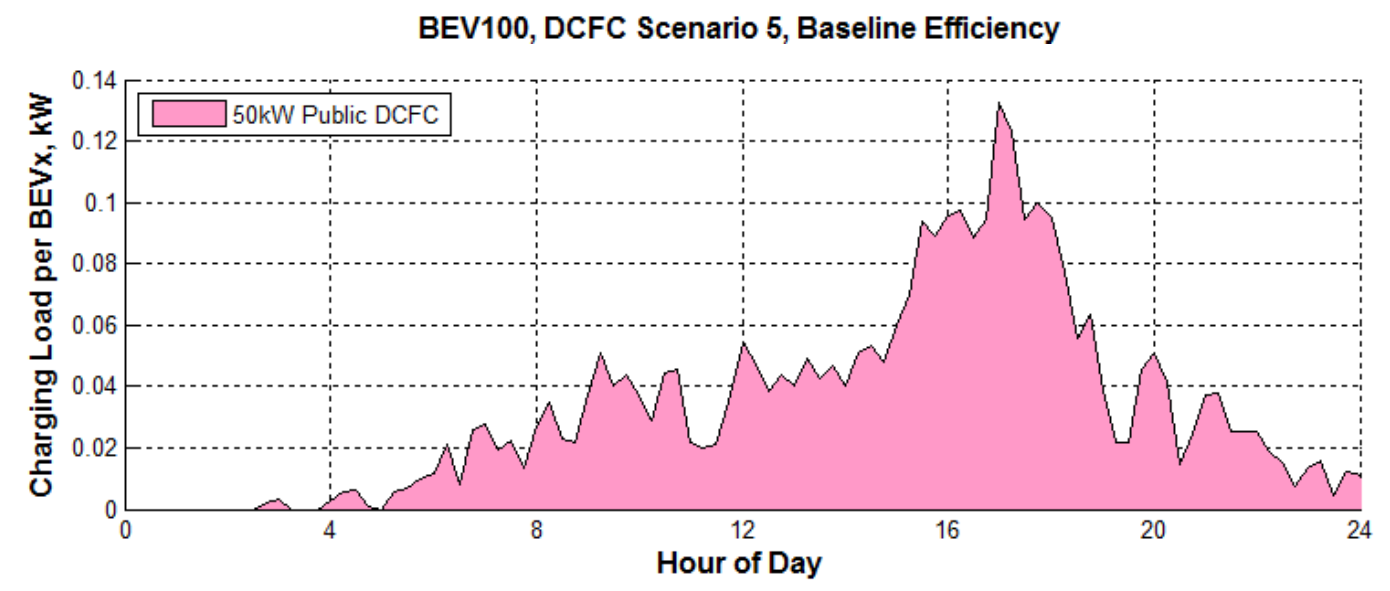

Figure 26. Simulated charging load profile by charger type (BEV100, DCFC Scenario 5, and baseline efficiency)

\subsubsection{Reduced Efficiency}

As the previous section demonstrated, DCFC consumer benefits and utilization are both sensitive to BEV electric range. Since BEV electric range is known to be sensitive to factors including driver aggression, ambient conditions, and battery degradation, a set of BLAST-V simulations was conducted assuming a 35\% reduction in nominal driving range. This level of reduction is representative of a range loss driving on a cold winter day in Colorado (Argonne National Laboratory 2012, FleetCarma 2013). 
Figure 27 shows the simulated eVMT results under the reduced efficiency scenario with colored bars in the foreground (results from baseline efficiency simulations shown in the background with grey bars). The value of the various DCFC networks is enhanced in situations where realworld vehicle range is below the rated value. Recall that the simulated FRTC vehicles were able to achieve approximately $85 \%$ of their desired miles in the baseline simulation with a BEV100 and no DCFC support. That value decays to less than $75 \%$ in the reduced efficiency scenario. The BEV200 and BEV300 are similarly penalized. However, the simulated DCFC networks allow nearly all of the lost eVMT to be regained with each BEV approaching its respective baseline efficiency eVMT value in DCFC Scenario 5.

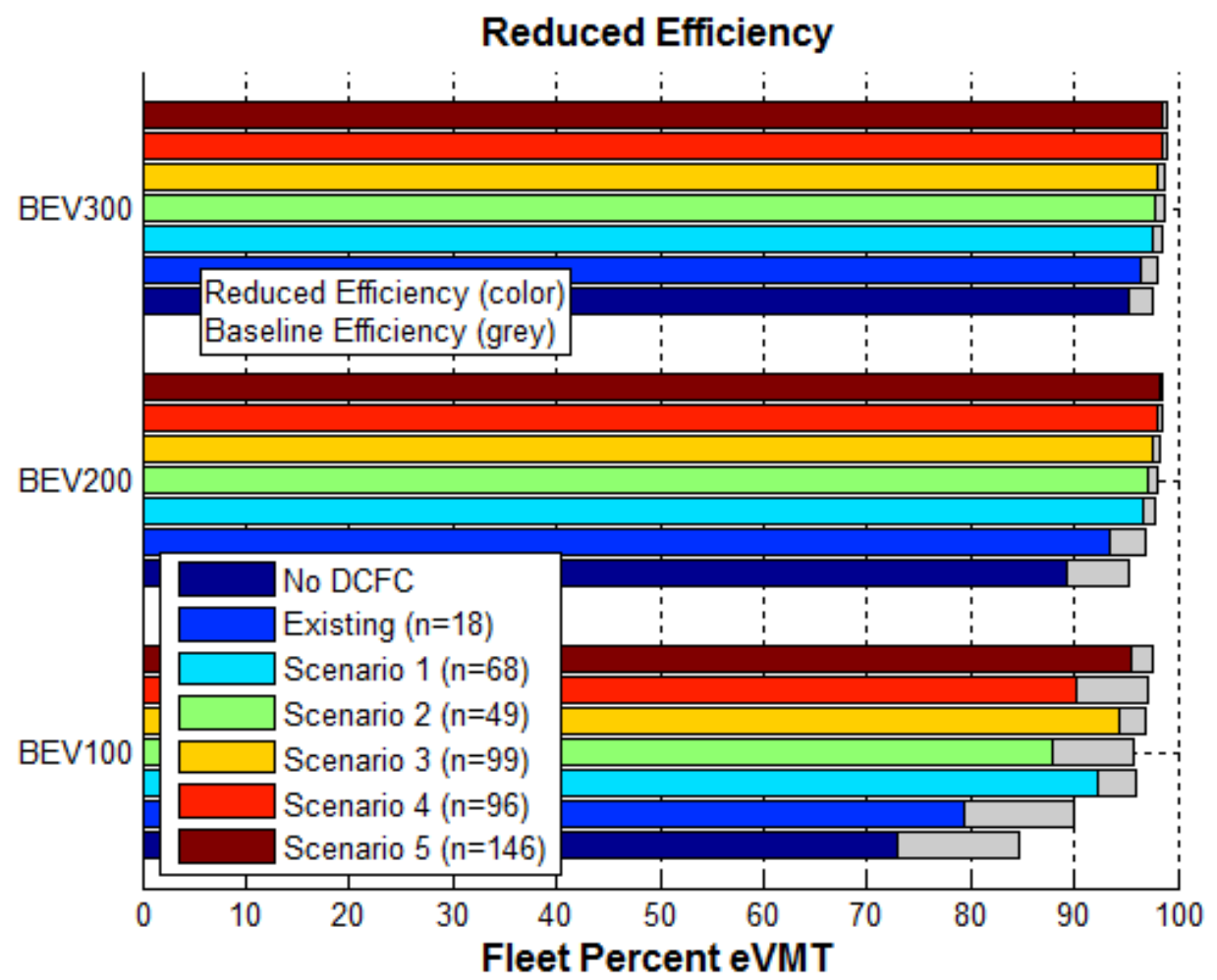

Figure 27. Simulated fleet percent eVMT by BEV type and DCFC network (reduced efficiency scenario) 
Reduced BEV driving range has a dramatic effect on simulated DCFC utilization. Figure 28 shows average daily utilization for the reduced efficiency scenario. While the impact of reduced vehicle range varies across scenarios, overall DCFC utilization approximately doubles in most instances.

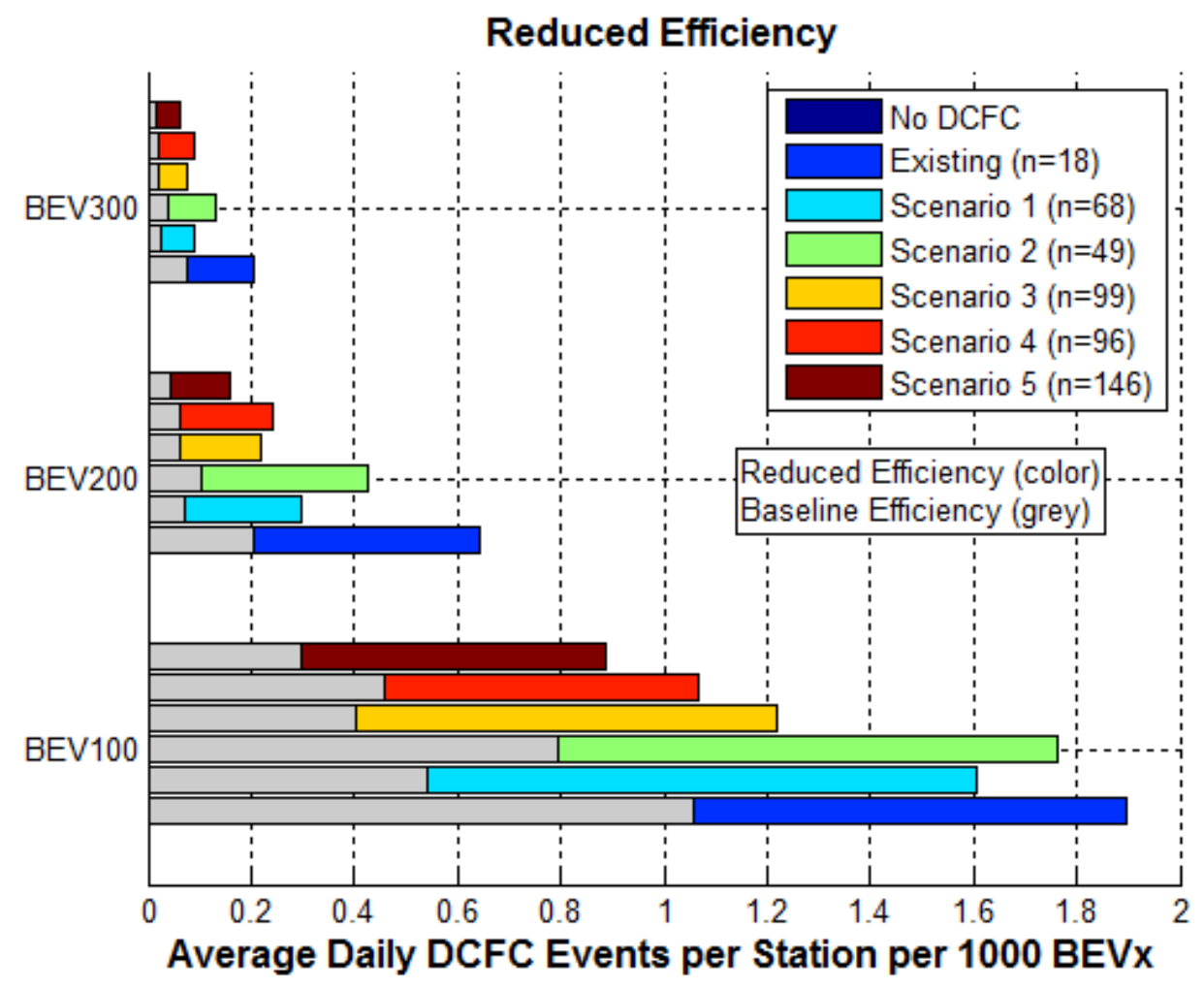

Figure 28. Simulated DCFC station utilization by BEV type and DCFC network (reduced efficiency scenario)

While overall DCFC station utilization is impacted by a simulated loss of vehicle efficiency, the spatial trends in utilization of public charging infrastructure are generally consistent with the baseline simulations as shown in Figures 29 through 31. 


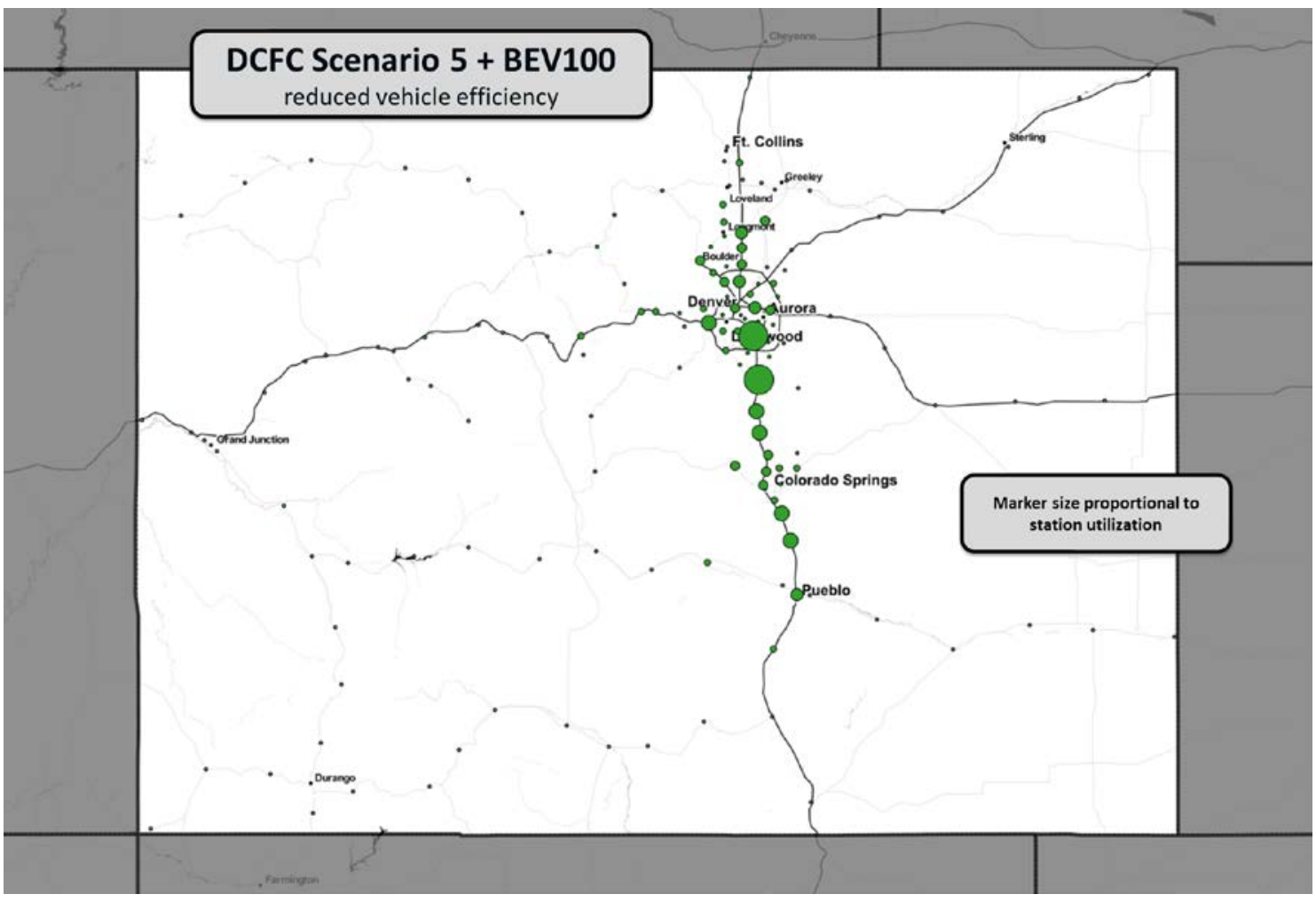

Figure 29. Simulated DCFC station utilization, marker size proportional to station charge events (BEV100, DCFC Scenario 5, and reduced efficiency)

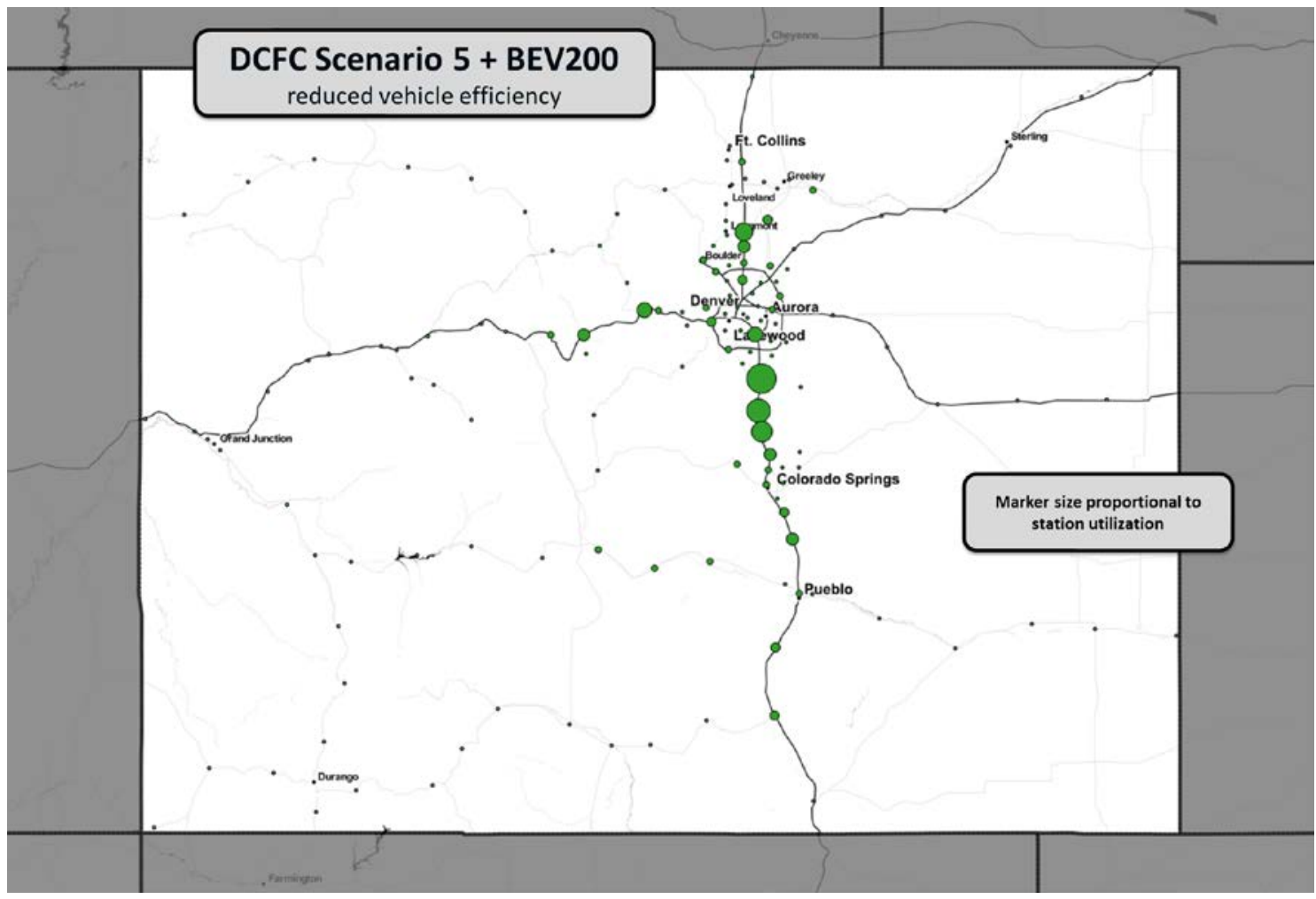

Figure 30. Simulated DCFC station utilization, marker size proportional to station charge events (BEV200, DCFC Scenario 5, and reduced efficiency) 


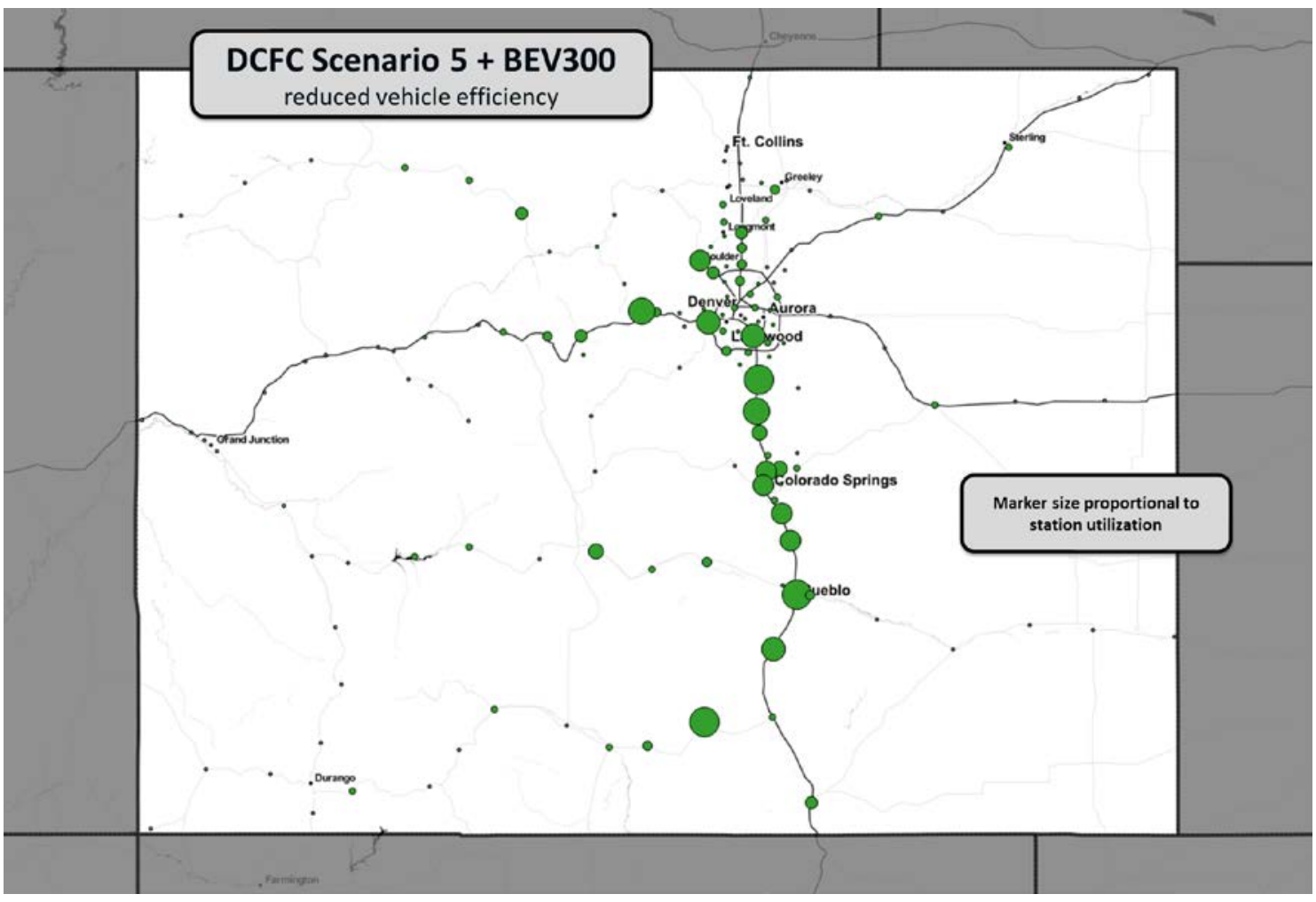

Figure 31. Simulated DCFC station utilization, marker size proportional to station charge events (BEV300, DCFC Scenario 5, and reduced efficiency)

\subsubsection{MUD Subset With No Home Charging}

BEV ownership is typically considered to be dependent on access to charging infrastructure at the vehicle's home location (for long-duration charging, typically overnight). For consumers with inconsistent access to home charging, a robust network of DCFC stations has been proposed as a potential alternative.

To explore this scenario, FRTC vehicle trajectories were segmented into two groups: 1) vehicles owned by residents of SUDs, and 2) vehicles owned by residents of all other dwellings types. MUD FRTC residence types included duplexes, apartment buildings, and mobile homes, and a final "other" classification used as a catch-all. The MUD subset of FRTC vehicles accounted for approximately $11 \%$ of all vehicles in the survey.

The MUD subset was simulated in BLAST-V using baseline vehicle efficiency for all BEV types and DCFC network combinations. Simulations were conducted both with vehicles having access to a Level 1 (L1) home charger and with vehicles having no access to home charging (effectively forcing consumers to rely exclusively on a public DCFC network in the model). The simulated eVMT results for all scenarios are shown in Figure 32 with the "no home charging" results shown in the foreground with colored bars and the L1 home charging results shown in the background with grey bars. 


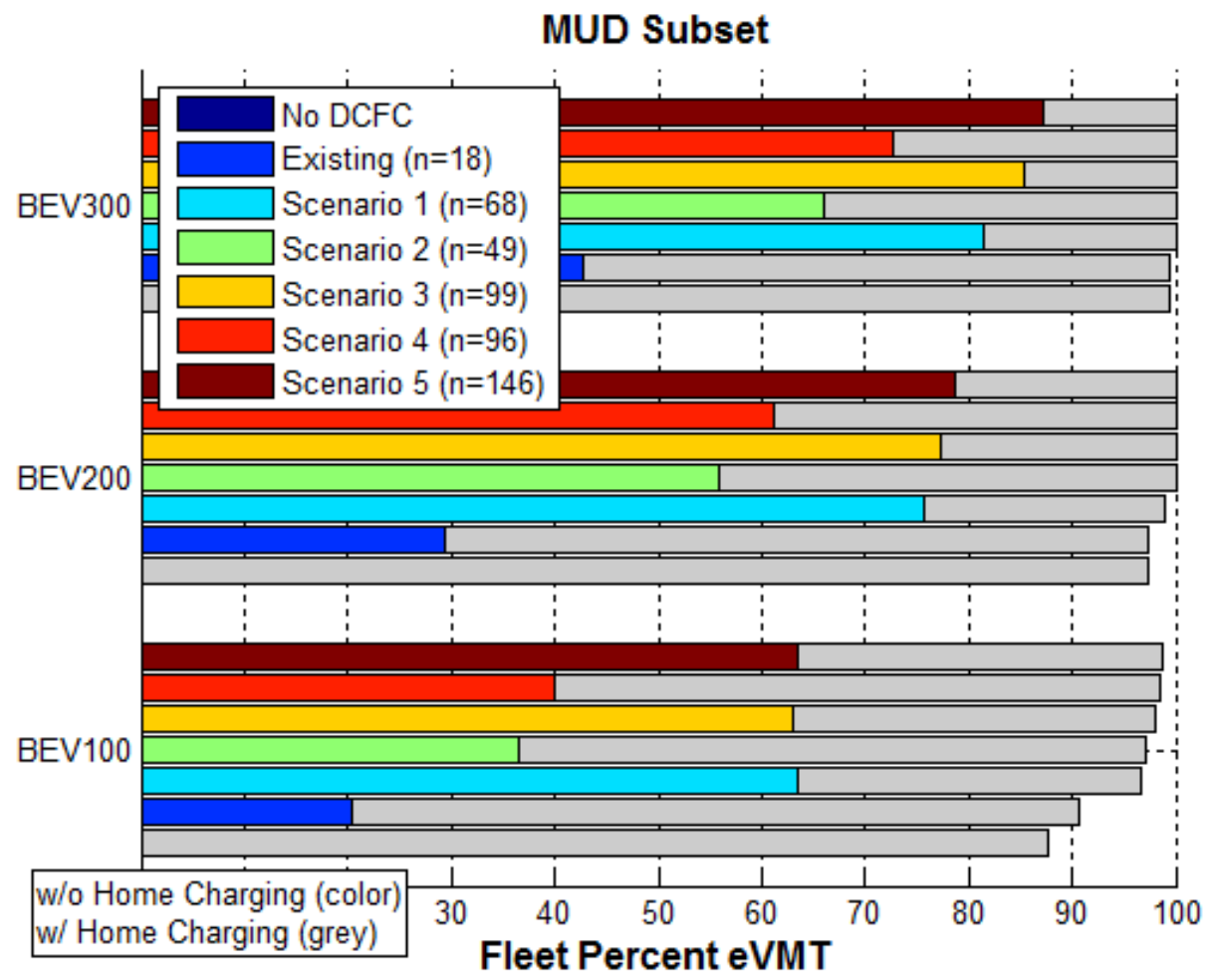

Figure 32. Simulated fleet percent eVMT by BEV type and DCFC network (MUDs only with no home charging)

Overall, simulated results for MUDs with home charging access (grey bars) reveal travel behavior consistent with the larger FRTC sample (including SUDs and MUDs). Simulated fleet percent eVMT for the MUD subset with home charging is approximately 2 to 3 percentage points greater than the comparable results presented in Section 5.2.1, implying slightly lower daily VMT values for the MUD subset.

The more interesting results are the simulations without home charging (colored bars in Figure 32) where eVMT are dramatically reduced in the absence of home charging (or other consistent Level 1 or Level 2 charging options). By definition, the simulations with no home charging stations and no public DCFC stations result in zero percent of desired miles being achieved. The most effective DCFC networks in the "no home charging" group are represented by Scenarios 1, 3, and 5. Recall that these three DCFC scenarios feature DCFC stations located based on maximizing exposure to aggregate traffic volumes, typically resulting in stations located in urban areas. Only marginal consumer benefits are realized when contrasting the 68 DCFC stations in Scenario 1 with the 146 DCFC stations in Scenario 5, which expands statewide charging coverage along the Colorado Interstate and highway systems. This result implies that for consumers with inconsistent access to home charging (MUD residents in this case), urban DCFC coverage is more beneficial than an inter-city network.

Furthermore, these simulations suggest that even a comprehensive DCFC network with good inter-city coverage and high access to urban stations, such as DCFC Scenario 5, fails to provide the same consumer benefits as an L1 home charger and no public DCFC access. For all three BEV types in this study, a higher fleet eVMT percentage was achieved with home L1 charging 
and no DCFC stations than was achieved with the 146 DCFC stations in Scenario 5 with no home charging. Despite the seemingly robust coverage provided by DCFC Scenario 5, a significant share of FRTC VMT remains uncovered. This shortfall is attributed to a relatively large share of trips that are unable to be routed near any of the simulated DCFC stations, a task that is particularly difficult for consumers with homes located far away from the nearest DCFC station, as was the case for a number of FRTC households on the outskirts of the Front Range urban areas.

While the simulated MUD consumers struggled to complete all of their desired trips without access to home charging, their increased reliance on public networks resulted in significantly higher DCFC utilization, as shown in Figure 33 (simulations without home charging shown with colored bars in background; simulations with home charging shown in foreground with grey bars). Restricting access to home charging for the MUD subset increased average DCFC station utilization by approximately an order of magnitude.

Spatial utilization results of the hypothetical DCFC Scenario 5 for the MUD subset are shown for all BEV types in Figures 34 through 36. As expected, DCFC utilization for the MUD subset without access to home charging is concentrated in Front Range urban areas, particularly in the Denver metropolitan area. This trend is consistent across the three BEV types.

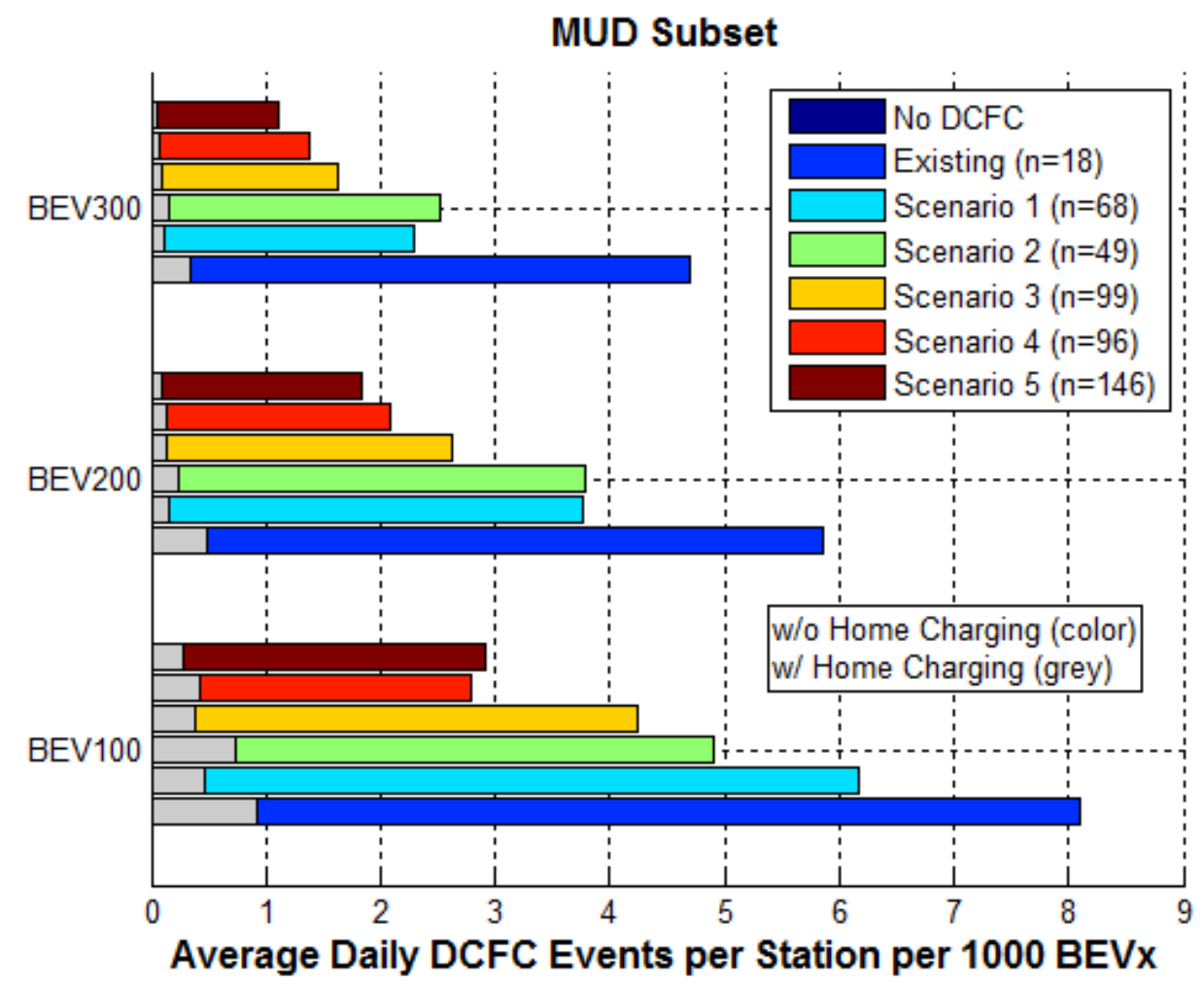

Figure 33. Simulated DCFC station utilization by BEV type and DCFC network (MUDs only with no home charging) 


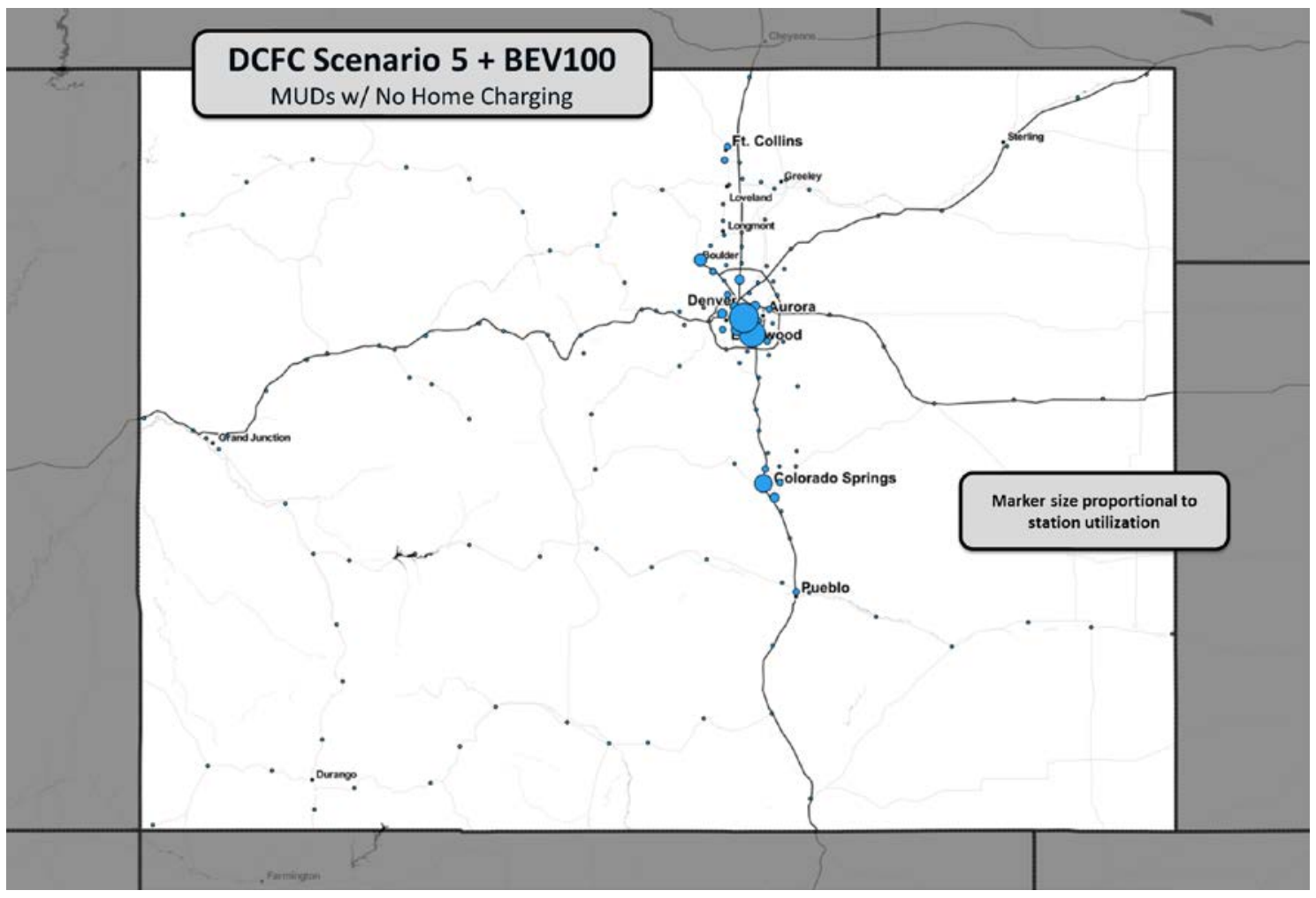

Figure 34. Simulated DCFC station utilization, marker size proportional to number of station charge events (BEV100, DCFC Scenario 1, and MUDs only with no home charging)

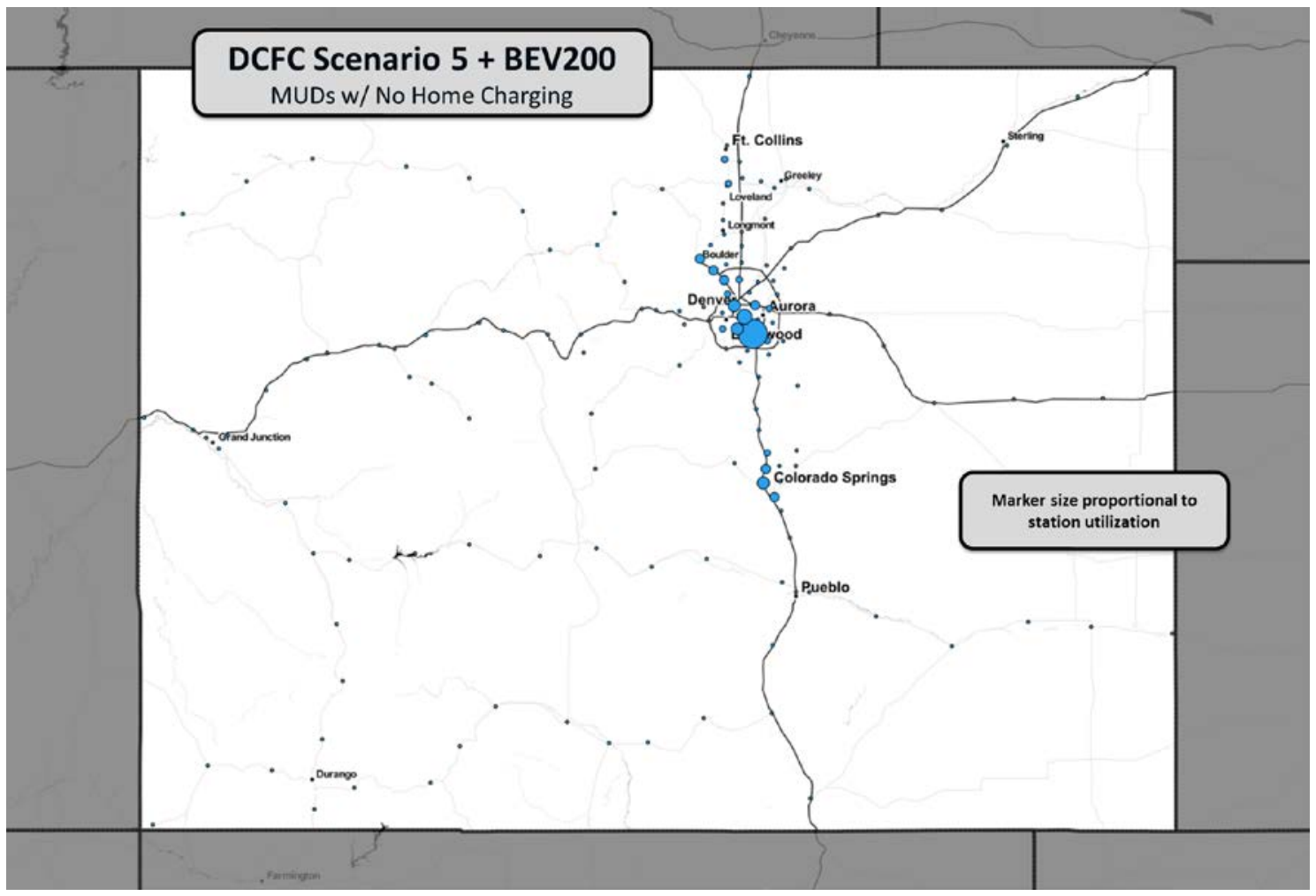

Figure 35. Simulated DCFC station utilization, marker size proportional to number of station charge events (BEV200, DCFC Scenario 1, and MUDs only with no home charging) 


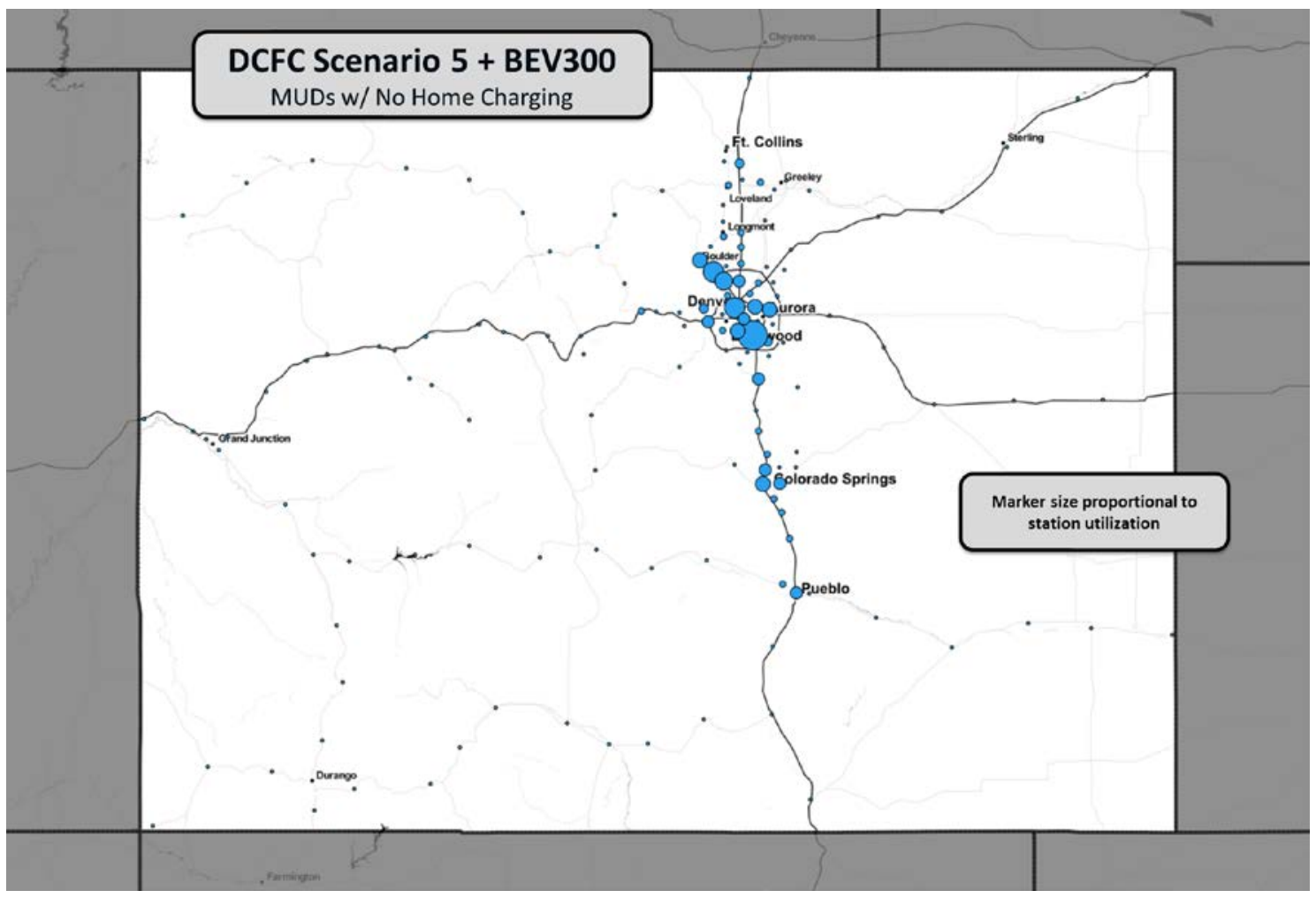

Figure 36. Simulated DCFC station utilization, marker size proportional to number of station charge events (BEV300, DCFC Scenario 1, and MUDs only with no home charging) 


\section{Summary}

A number of hypothetical DCFC networks for Colorado were evaluated using NREL's BLAST$\mathrm{V}$ model with weekday consumer travel patterns quantified by FRTC survey data. The value of each DCFC network to consumers was quantified by simulating incremental eVMT benefits relative to three BEV types: BEVs with ranges of 100,200 , and 300 miles. Results indicate that a robust DCFC network is most valuable to BEVs with relatively short, single-charge driving ranges (the simulated BEV100 in this work); although DCFC in more remote areas have the greatest utility for BEVs with relatively long ranges (the simulated BEV300 in this work). DCFC demand was shown to be greatest along inter-city corridors, particularly along the I- 25 corridor connecting Colorado's largest population centers. Demand along the mountainous stretch of I-70 west of Denver is likely underestimated in this work due to FRTC data being limited to weekday travel.

From the DCFC operator's perspective, station utilization was quantified for all combinations of BEV types and DCFC networks. Simulation results are expected to provide realistic, near-term expectations for DCFC utilization, with the most optimistic scenario resulting in approximately one daily DCFC event per station per 1,000 BEVs. Modeling suggests that while average DCFC station utilization is expected to improve as the Colorado BEV market grows, the success of longer range BEVs and DCFC network growth is expected to curb average utilization on a perstation basis. Temporally, DCFC utilization has the potential to add to grid loads in the late afternoon and early evening hours (often coincident with peak demand for travel and electricity generation). The ill effects of this new electrical load could potentially be offset by time shifting the charging load at home locations or employing distributed storage/generation alongside DCFC stations.

A sensitivity study of vehicle efficiency demonstrated that the value of DCFC networks to consumers increases in situations where vehicle range is compromised (due to extreme ambient conditions resulting in additional energy requirements to heat or cool the battery and cabin). In turn, simulating diminished vehicle efficiency induces increased levels of DCFC utilization.

A subset of simulations for MUDs was conducted to evaluate the potential for DCFC networks to serve as the sole source of charging for consumers with inconsistent access to charging at their home (or other regular parking) locations. While a robust network of DCFC stations was able to replace some of the value of home charging, modeling revealed that a larger DCFC network than the hypothetical scenarios considered in this work would be required to fully replace the consumer benefits of home charging.

As the State of Colorado considers opportunities to expand its network of DCFC stations through a combination of public and private investment, it is the authors' hope that this report will serve as an analytic resource for planning that enables expanded consumer adoption of BEVs and sustainable business models for DCFC station operators. 


\section{References}

Argonne National Laboratory, Advanced Powertrain Research Facility, "Downloadable Dynamometer Database: 2012 Nissan Leaf.” Accessed April 28, 2017, https://www.anl.gov/energy-systems/group/downloadable-dynamometer-database/electricvehicles/2012-nissan-leaf

CDOT Nominations for FAST Act Designation of Alternative Fuel Corridors in Colorado. https://www.codot.gov/programs/planning/documents/resources/alt-fuel/alt-fuel-corridors2016

Colorado Energy Office. "Electric Vehicle Market Implementation Study" https://www.colorado.gov/pacific/sites/default/files/atoms/files/EV\%20Market\%20Study $\% 2020$ 15 0.pdf

Davis, M., and M. Alexander. Guidelines for Infrastructure Planning: An Explanation of the EPRI Red Line/Blue Line Model. EPRI, Palo Alto, CA: 2014. 3002004096. http://www.epri.com/abstracts/Pages/ProductAbstract.aspx?ProductId=000000003002004096

Department of Environmental Health, City and County of Denver. Denver's Opportunity for Vehicle Electrification: Overcoming Charging Challenges to Maximize Air Quality Benefits. Southwest Energy Efficiency Project (SWEEP), Boulder, CO, forthcoming.

FleetCarma. "Electric Range for the Nissan Leaf \& Chevrolet Volt in Cold Weather." Accessed April 28, 2017, http://www.fleetcarma.com/nissan-leaf-chevrolet-volt-cold-weather-range-losselectric-vehicle/

Francfort, Jim, Shawn Salisbury, John Smart, Thomas Garetson, and Donald Karner. 2017. Considerations for Corridor and Community DC Fast Charging Complex System Design. Idaho Falls, ID: Idaho National Laboratory, Report No. INL/EXT-17-40829. https://avt.inl.gov/sites/default/files/pdf/reports/DCFCChargingComplexSystemDesign.pdf.

Idaho National Laboratory, The EV Project, "What Were the Use Patterns Observed at the Highly Utilized Direct Current Fast Charge Sites?” June 2015, https://avt.inl.gov/sites/default/files/pdf/EVProj/WhatWereTheUsePatternsObservedAtHighlyUti $\underline{\text { lizedDCFCSites.pdf }}$

IHS Automotive. https://www.ihs.com/industry/automotive.html

Melaina, Marc, and Michael Helwig. 2014. California Statewide Plug-In Electric Vehicle Infrastructure Assessment. Prepared by the National Renewable Energy Laboratory for California Energy Commission. Publication Number: CEC-600-2014-003. http://www.nrel.gov/docs/fy15osti/60729.pdf

Neubauer, J., and E. Wood. 2014. "Thru-Life Impacts of Driver Aggression, Climate, Cabin Thermal Management, and Battery Thermal Management on Battery Electric Vehicle Utility." Journal of Power Sources Vol. 259, 262-275, http://www.sciencedirect.com/science/article/pii/S0378775314002766 
Randall, T. 2017. "The Electric-Car Boom is So Real Even Oil Companies Say It's Comin." Bloomberg New Energy Finance, April 25, available at:

https://www.bloomberg.com/news/articles/2017-04-25/electric-car-boom-seen-triggering-peakoil-demand-in-2030s

U.S. Department of Energy, Alternative Fuels Data Center. "Alternative Fueling Station Locator." http://www.afdc.energy.gov/locator/stations/

U.S. Department of Transportation, Federal Highway Administration, Office of Highway Policy Information. "HPMS Public Release of Geospatial Data in Shapefile Format." Accessed April 1, 2017, https://www.fhwa.dot.gov/policyinformation/hpms/shapefiles.cfm

Volkswagen Group of America. 2017. "National ZEV Investment Plan: Cycle 1.” April 9. https://www.epa.gov/sites/production/files/2017-04/documents/nationalzevinvestmentplan.pdf

Wood, E., J. Neubauer, and E. Burton. 2015. "Quantifying the Effect of Fast Charger Deployments on Electric Vehicle Utility and Travel Patterns via Advanced Simulation." SAE Technical Paper 2015-01-1687, doi:10.4271/2015-01-1687. Preprint:

http://www.nrel.gov/docs/fy15osti/63423.pdf

Wood, E., S. Raghavan, C. Rames, J. Eichman, and M. Melaina. 2017. Regional Charging Infrastructure for Plug-In Electric Vehicles: A Case Study of Massachusetts. Golden, CO:

National Renewable Energy Laboratory, Technical Report NREL/TP-5400-67436. http://www.nrel.gov/docs/fy17osti/67436.pdf. 